
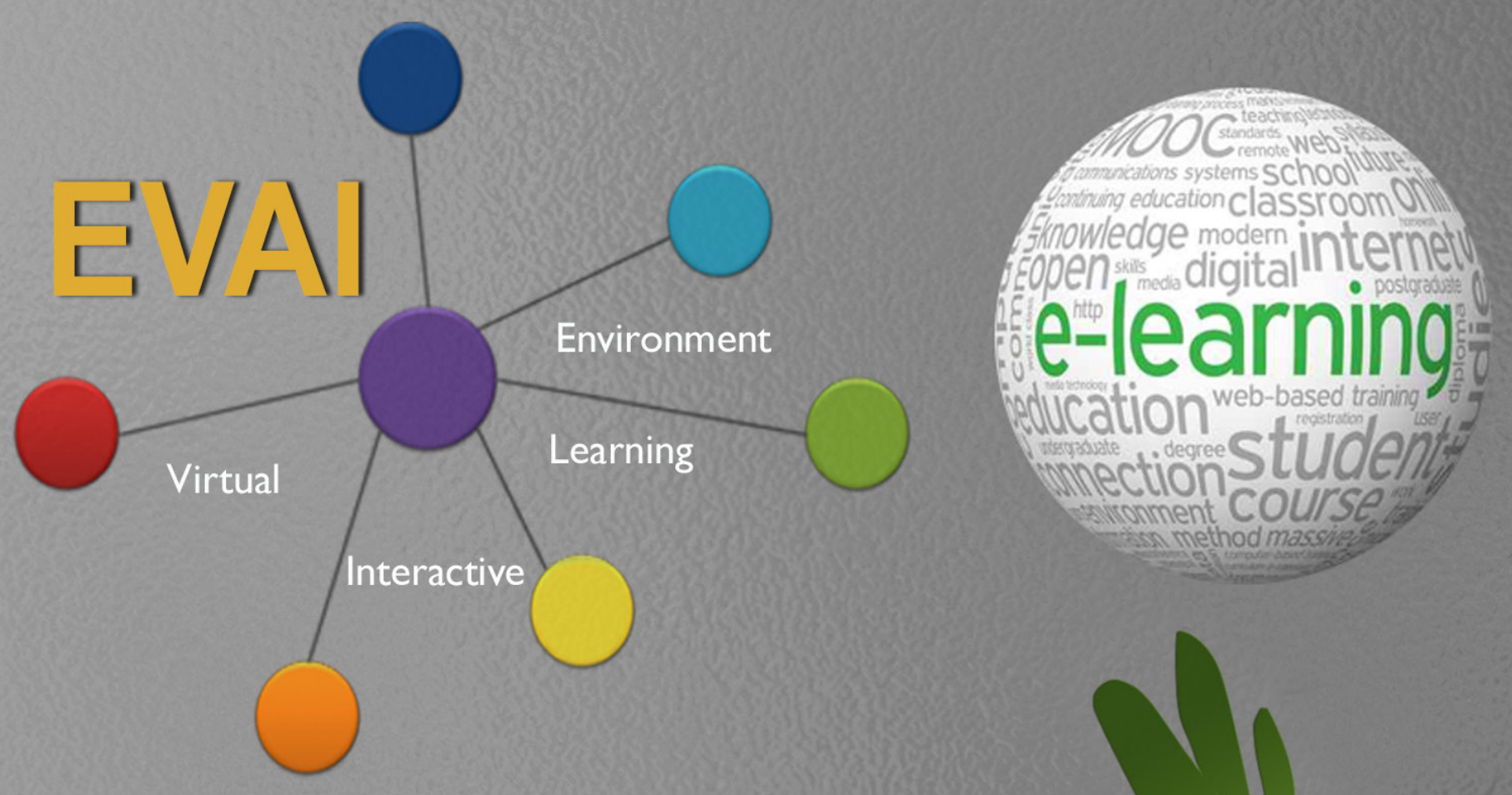

\title{
EVAI
}

\section{E-LEARNING PLATFORM:}

\section{STUDENT'S REFERENCE GUIDE}

\author{
Antonio Grandío Botella \\ Rosa Ana Peris Pichastor \\ Raquel Agost Felip \\ Óscar Climent Nacher \\ Inma Echarri San Adrián
}

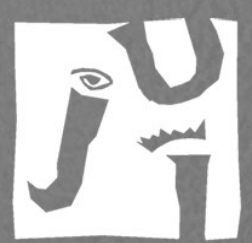

\section{COL-LECCIO educació}

UNIVERSITAT

JAUME•I 
EVAI

E-LEARNING PLATFORM: STUDENT'S

\title{
REFERENCE GUIDE
}

\author{
COL-LECCIO \\ educació
}

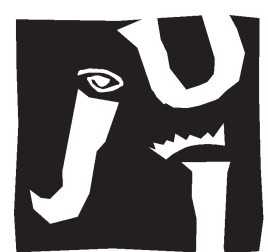

UNIVERSITAT

JAUME• | 


\section{BIBLIOTECA DE LA UNIVERSITAT JAUME I. Dades catalogràfiques}

EVAI: e-learning platform : student's reference guide [Recurs electrònic] / Antonio Grandío Botella ... [et al.] —Castelló de la Plana: Publicacions de la Universitat Jaume I, 2014

1 recurs electrònic - (Educació ; 18)

e-ISBN 978-84-697-1180-4

1. Ensenyament virtual. I. Grandío Botella, Antonio. II. Universitat Jaume I. Publicacions. III. Sèrie: Educació (Universitat Jaume I) ; 18

004.738.5:37

UT

JNV

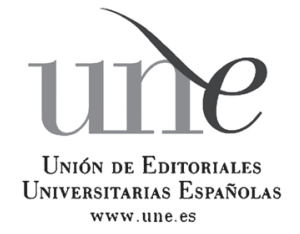

(9) $(1) \Theta$
Publicacions de la Universitat Jaume I és una editorial membre de l'une, cosa que en garanteix la difusió i comercialització de les obres en els àmbits nacional $\mathrm{i}$ internacional. www.une.es.

Aquest text està subjecte a una llicència Reconeixement-CompartirIgual de Creative Commons, que permet copiar, distribuir i comunicar públicament l'obra sempre que s'especifique l'autor i el nom de la publicació fins i tot amb objectius comercials i també permet crear obres derivades, sempre que siguen distribuïdes amb aquesta mateixa llicència.

http://creativecommons.org/licenses/by-sa/3.0/legalcode

Edita: Publicacions de la Universitat Jaume I. Servei de Comunicació i Publicacions, 2014 Campus del Riu Sec. Edifici Rectorat i Serveis Centrals. 12071 Castelló de la Plana www.tenda.uji.es e-mail: publicacions@uji.es

Fax: 964728232

ISBN: 978-84-697-1180-4

DOI: http://dx.doi.org/10.6035/Educacio.2014.18

Maquetació: GRUP FENT 
EVAI

\section{E-LEARNING PLATFORM: STUDENT'S REFERENCE GUIDE}

Antonio Grandío Botella

Rosa Ana Peris Pichastor

Raquel Agost Felip

Óscar Climent Nacher

INMA ECHARRI SAN AdrIÁN

\section{COL-LECCIO \\ educació}

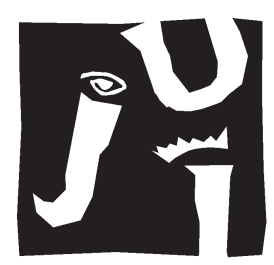

UNIVERSITAT

JAUME•I 
i n d e $\quad$ d

PRESENTATION

INTRODUCTION

CHAPTER I: LOGIN PAGE

CHAPTER 2: HOMEPAGE. WHAT'S ON IT?

2.I. CALENDAR

2.2. CENTRAL TASKBAR (LEFT)

2.3. CENTRE SECTION

2.4. RIGH-HAND PART

2.5. SIDEBAR (LEFT) 


\section{P R E S E N TATIO N}

The emergence of Global Consciousness is not a one-dimensional fact. The advances made in countless fields of science and, above all, in technology have played a fundamental role in this ubiquitous change. More particularly, the Information, Communication and Knowledge Technologies (ICKT) have given rise to a radical shift in human world views towards a Global Consciousness. And the change that comes with them seems to possess one of the basic dimensions of Global Consciousness, namely holism.

We must realise that the shift begun by the globalisation of the markets was a unilateral change tied to economic and commercial aspects, and few of us believe that it has had a positive impact. In fact, the unprecedented planetary crisis we are currently undergoing seems to be the result of that globalisation.

Yet, the revolution that the ICKTS are bringing with them, although accompanied by many threatening aspects linked to freedom and privacy, have a different look about them. This becomes especially apparent when we consider the latest stages related to the mushrooming of virtual social networks. Indeed it is usually accepted -and we are of the same opinion- that the traditional «world view» that sees these technologies as ICKTS has to be changed for another one that is more in line with the reality emerging from them as of the WEB 2.0, such as PETS (Participation \& Empowerment Technologies).

In this swift evolution up until PETS, and without wishing to be too rigorous, we could distinguish three stages, loosely covering a decade each:
Computing (80-90), the Internet (90-00) and Virtual (00-to date). Essentially the leading players in computing were the Personal computer (PCS and Macs), the Operating System (Unix, MSDOS, Windows, OS, etc.) and the applications that were run inside it. At that time, the star in education was undoubtedly the multimedia CDROM. Classes were still conducted on a face-to-face basis and teachers used CDS as a teaching aid. The networks that existed at that time were all local (LANS).

Nevertheless, an important step forward was taken in the Internet decade (WEB I.0), where the leading figures were now the Web Browser and the Worldwide Web (Internet). Digital communication became firmly established with email, forums, chat-rooms, instant messaging and videoconferences. It was at this point when training underwent a drastic change, since the use of Online contents and the emergence of distance education (d-learning) and, later on, e-learning platforms revolutionised the field.

The Virtual stage (WEB 2.0 and beyond), on the other hand, is characterised by having the social network as its meaningful application, applications are all web-based and the physical network is also wireless (WIFI in WLAN and GPRS UP to HSPA and HSPA + in mobile internet). Mobile devices (smartphones, etc.) appear as alternatives to the computer (this mobility stage has been dubbed by many as 3.0). New applications such as Blogs, Wikis, Rss and Mashups also appear. At this point we should stress that we are not talking so much of a new technology but rather of the creative use of already-existing technologies, with the 
exception of network and/or GPS geo-referencing. In this stage, digital communication takes place in virtual environments and social networks that integrate all the features we have just mentioned. Moreover, training uses virtual e-learning platforms and opens itself up to mobile devices -m-learning (mobile) - which allow new more informal and collaborative forms of learning and education to emerge, rather than being based on the classic institutions (schools, colleges, universities, etc.). In this line, the Wikipedia is a good example.

In view of the foregoing, the EVAl (from the Spanish for Interactive Virtual Learning Environment) is currently evolving to adapt itself to the last stages outlined above. Without playing down the importance of the other elements, and given the space limitations of this presentation, let us now move on to briefly describe what e-learning platforms, and more specifically the EVAl (which is now available for m-learning - EVAl ApP), have to offer in terms of training.

I would like to point out that the EVAl is an active, dynamic constantly mutating project whose operative manifestation is the virtual platform we present here as it stands today. The EVAl is not just an online teaching-learning "platform». Rather, it is a teaching and learning philosophy that is shared and experienced in real time and which renews and regenerates itself through the interaction among its users (teaching staff and learners). It is at the same time both pragmatic and abstract because it gradually constructs itself, day by day, as we think, use it and represent it.
Conceived in this way, then, the EVAl is also an open project, written in free software, that attempts to uncover the new realities that emerge with the intensive and innovative use of the ICKTS in Education. This is accomplished by becoming immersed in both the virtual and the real face-to-face world, and by learning to make sense -in real time- of the different patterns that are formed.

In turn, and taking into account its current status as a learning application, it fulfils all the standard requirements to be considered an e-learning platform: there are different levels of users (teaching staff and students, for example) and communication is synchronous (chat-rooms and classes via videoconference) and asynchronous (forums, email and IM). As is already well known, in the new tendencies in education, the teacher's role is now that of a guide and the student becomes the focus of the training process, responsible for self-managing his or her own learning. And this has been taken into account while the project was being put together.

In this sense, then, and in order to make it easier for the user to become familiar with the EVAl platform, the pages that follow offer all the information needed to be able to move around inside the environment without difficulty. First of all the structure of the platform is outlined and then guidance is provided on how to operate the information, communication and knowledge tools contained within it.

Antonio Grandío Botella 


\section{N T R O D U C T I O N}

The EVAl platform is a virtual learning (e-learning) environment based on open-source free software.

At the software level, and like other platforms such as Moodle, it uses the Internet infrastructure system known as WAMP (Windows, Apache, MySql/MariaDB and PHP). This means that is an Open Source Project.

The EVAl is part of a dynamic, constantly evolving project. Its development is the result of the research, experimentation and ideas that have arisen from its use by teaching staff and students, since it is the «virtual classroom» in different graduate and postgraduate courses (Official and University-specific courses at the Universitat Jaume I).

The EVAl platform offers its users the following tools:

I. Multilevel online Internet Forums (by subjects or global). Their use encourages general communication and cooperation between students and teaching staff.

2. Instant Messaging application (EVAI Messenger). This enables users to send messages and files offline as well as Videoconference. It encourages individual communication and cooperation between students and teachers. There is also a mass email and/or SMs messaging service.

3. Insertion of links associated to the user following prior verification of their existence (in databases and/or Internet).
4. Reciprocal Self-Assessment among students with real-time measures of centrality and dispersion. This encourages competitiveness among students.

5. Numeric Ranking of insertions per student that allows consultation of the personal profile and selective contribution of each student by means of hyperlinks. This encourages competitiveness.

6. Online Tutorial about How to use EVAl.

7. Online Video Library of Recorded Classes (audio recordings of practicals) and/or linked to external sources (i.e. Youtube etc.).

8. Individual Folders, for Groups and Global. Online space for saving, sharing and managing files.

9. Individual and Teachers' Scheduler.

10. Multiple chat rooms at any level (can be saved).

II. Multilanguage support (currently Spanish, Valencian and English), can be personalised by the user.

12. Class photo gallery for each subject.

13. Notice board. This can be configured to send notices automatically by email.

14. Interactive Knowledge Manager: Guided Virtual Learning.

I5. Voice Synthesis System (that can be activated at will by the teacher) that greets users on 
logging in and informs them of their current values (number of links inserted out of a total of $x$, whether they have any messages from other users, how many links they have voted for, how many votes they have received, the mean score they have been given and the standard deviation). It also reads the summaries of each link on being requested to do so by the user.

16. Full access by the Internet and ready for use with Smartphones, Tablets and iPads (anyone with a Smartphone or Tablet with Wifi or $3 G / 4 G$ can access the portal).

17. FAQs, Creation of Assessments with automatic correction, Exam results, Online Qual- ity Questionnaire (updated in real time) by means of self-assessment and the users' proposals for continuous improvement.

18. In situ design of Research Questionnaires.

19. Tracking attendance and time spent, last login and IP.

20. User's personal profile. Here the level of data privacy can be set. Specific space per subject for uploading assessment task files.

21. System of distance classes with the aid of Google Hangouts. This enables virtual classes to be taught using video, audio and synchronised slides and live chat. 


\section{LOGIN PAGE}

To access the EVAl e-learning (see Figure I) platform we have to enter the username and password we were given by the course administrator.

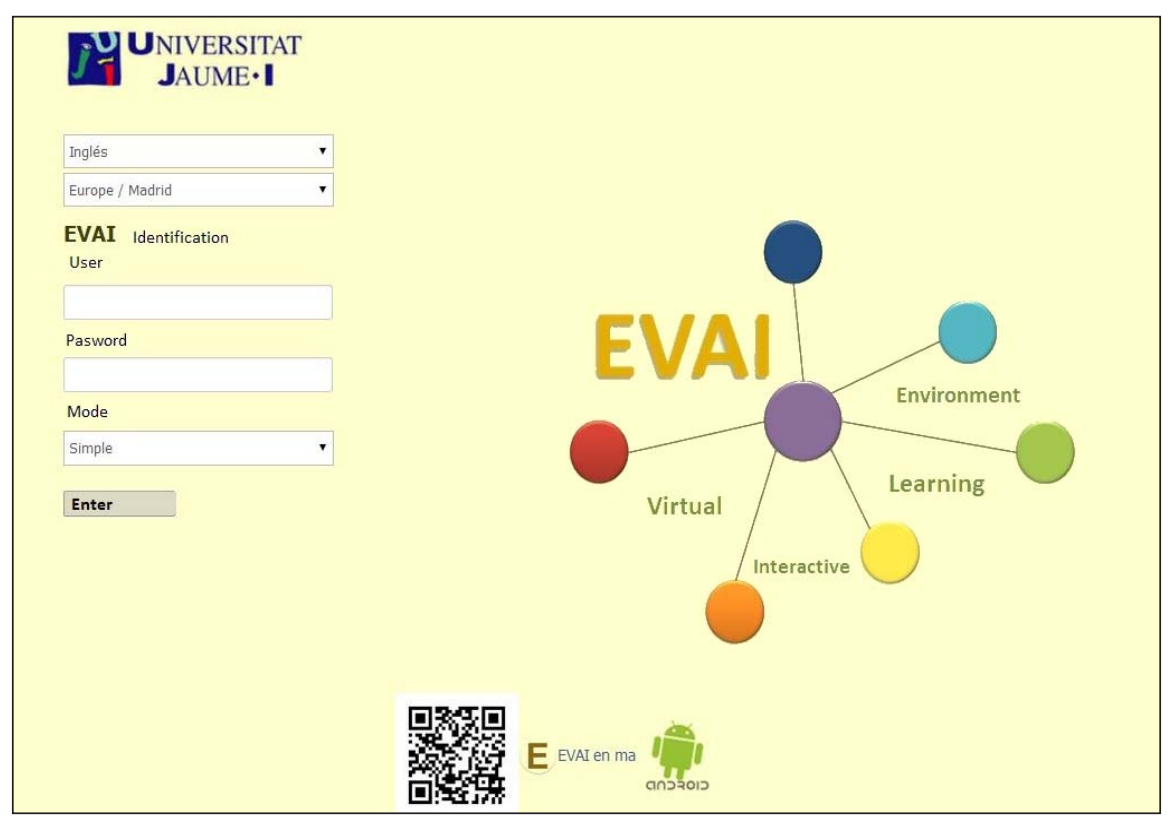

Figure 1. Platform access

Additionally, we can choose the mode of access (recommended option is Simple mode), language and region.

We then click on the Enter button, as is shown in Figure 2, which will take us to a similar screen, shown in the screenshot below.

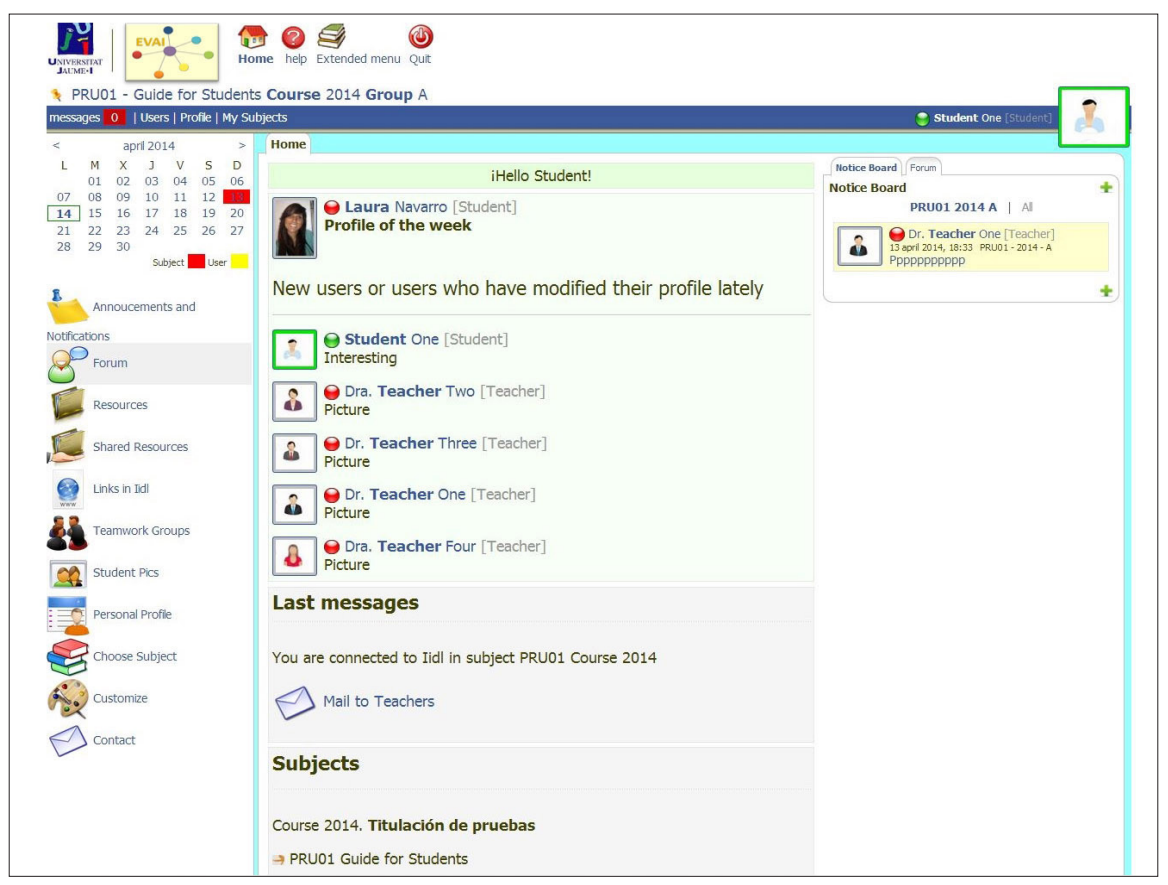

Figure 2. Initial Screen 


\section{HOMEPAGE. WHAT'S ON IT?}

\section{UPPER PART OFTHE SCREEN}

Starting from the upper part of the screen, there are 4 icons:

\begin{tabular}{|l|l|}
\hline $\begin{array}{c}\text { Home } \\
\text { Home }\end{array}$ & Start. Always takes us back to the homepage. \\
\hline & Exit. Allows us to leave the platform. \\
\hline Exit & Help. Provides help on how to use the platform \\
\hline $\begin{array}{c}\text { Expanded } \\
\text { Menu }\end{array}$ & $\begin{array}{l}\text { Expanded Menu. Clicking on this icon allows us access to a menu with more } \\
\text { advanced options... }\end{array}$ \\
\hline
\end{tabular}

Immediately below these icons we can see the name of the subject we are in. Clicking on the name of the subject will display a list of all the subjects in the course and allow us to change subject (provided they are activated).

To the far right we can see the name and photo (if one has been uploaded) of the person who has accessed the platform. The words 'student' or 'teacher' will appear beside the name, depending on their status in the course. Clicking on the word allows access to their personal homepage.

\section{I.}

\section{CALENDAR}

At the top left of the screen we will see the calendar or diary (Figure 3), where the days on which documents of general interest for the course and/or notices were uploaded are marked with a red square and today's date is highlighted in gree. The icon differences if there is a new or a file type.

Clicking on the days that are marked grants us access to that day's documents and/or latest notices; clicking on the month enlarges the calendar and we can Add notes by clicking on the icons at the top of the screen.

\section{2.}

\section{CENTRALTASKBAR (LEFT)}

In the middle at the top, next to the calendar and below the name of the subject, at the same height as the name of the user who is connected, we can find the following sections and subsections: 


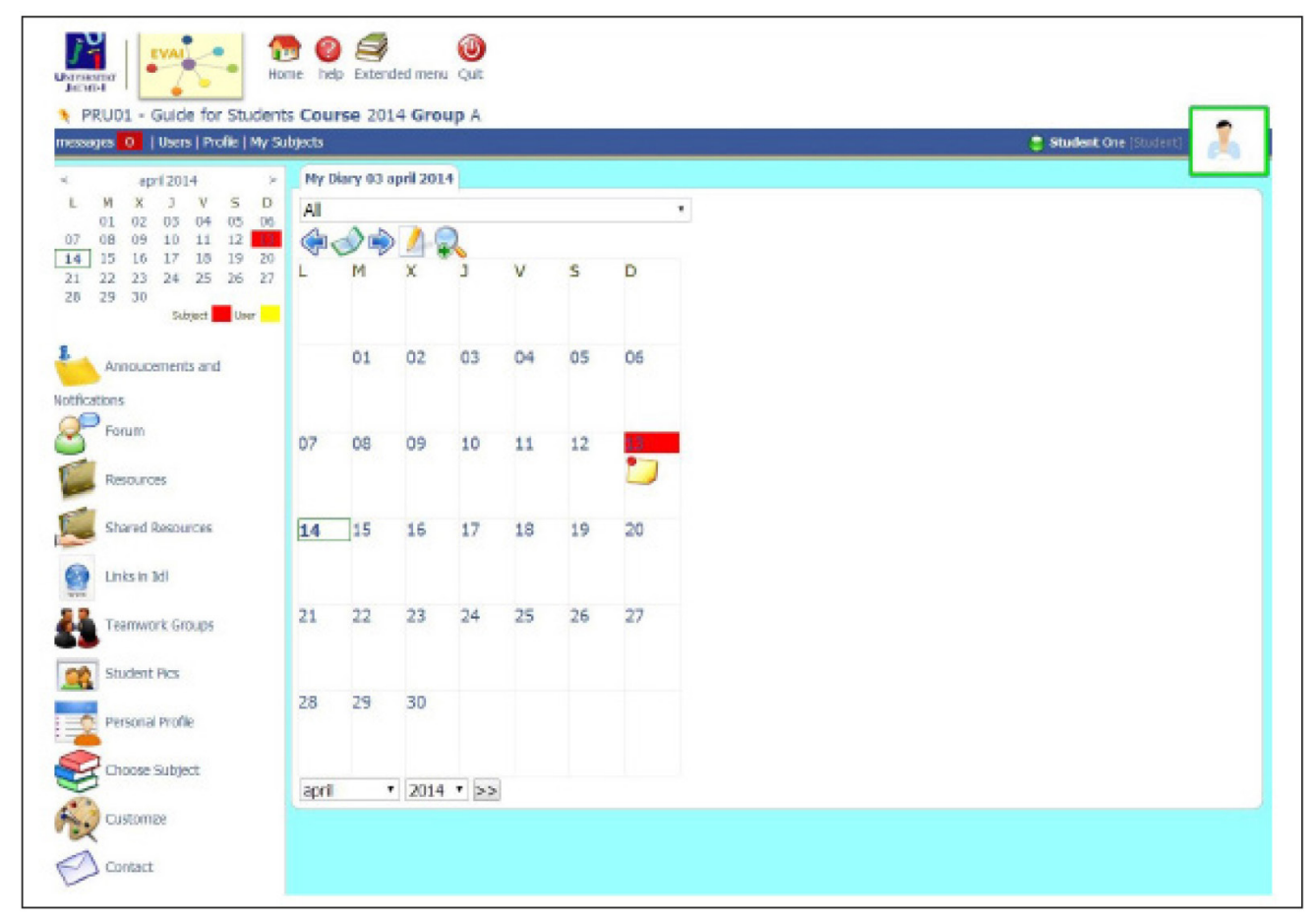

Figure 3. Calendar or diary

\section{MESSAGES}

In the Messages section (Figure 4) we can access our messages in the EVAI-Messenger feature (Figure 5a). A number in the icon other than 0 tells us that we have unread messages.

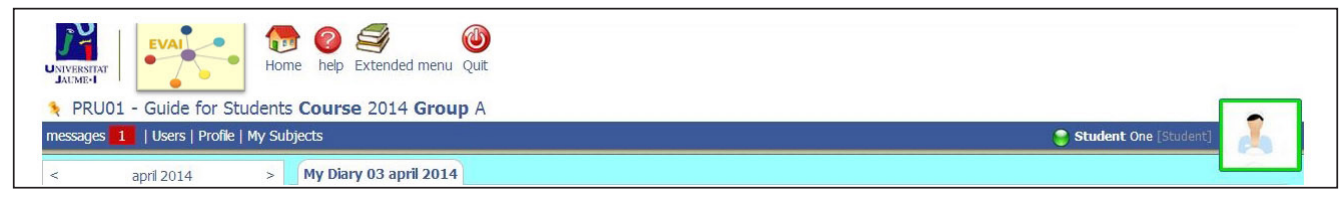

Figure 4. Messages section

Clicking on the word messages allows us to view the unread messages.

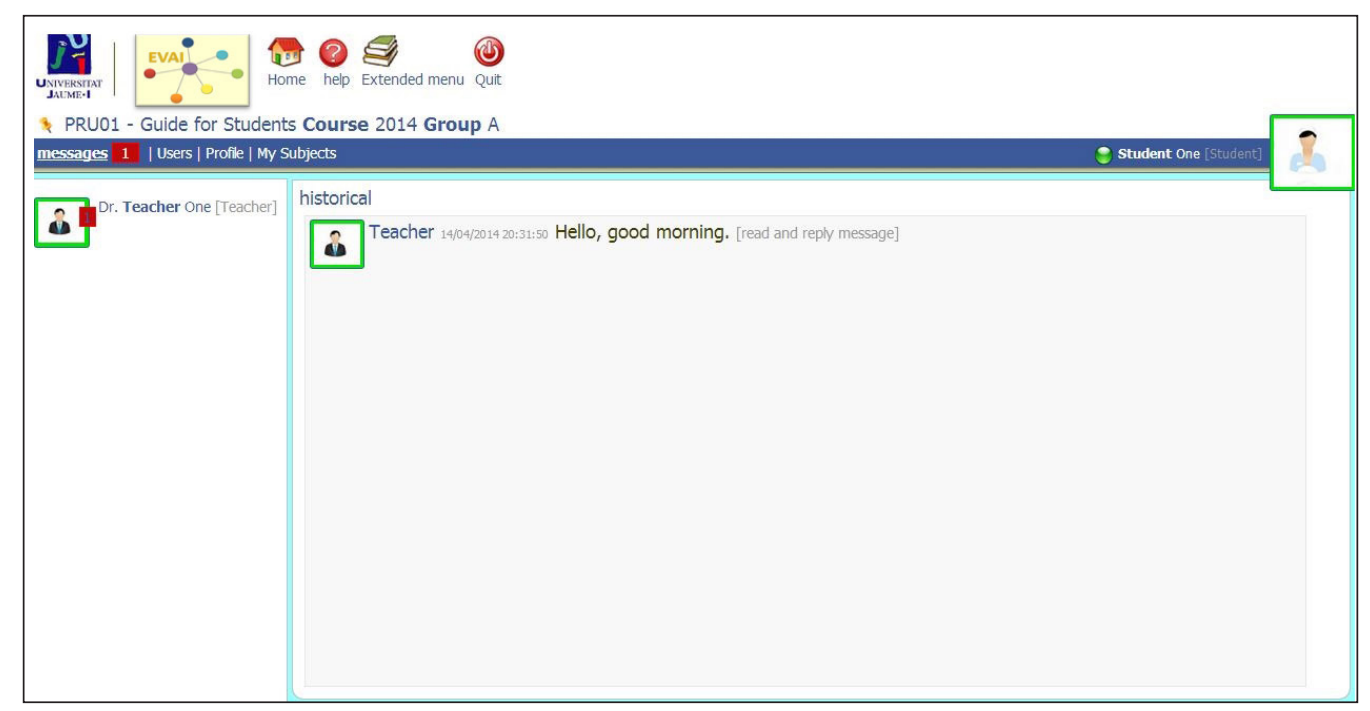

Figure 5a. EVAl-Messenger 
To answer, we click on the user and message we want to reply to and this will bring up a box in which we can write our answer (Figure 5b).

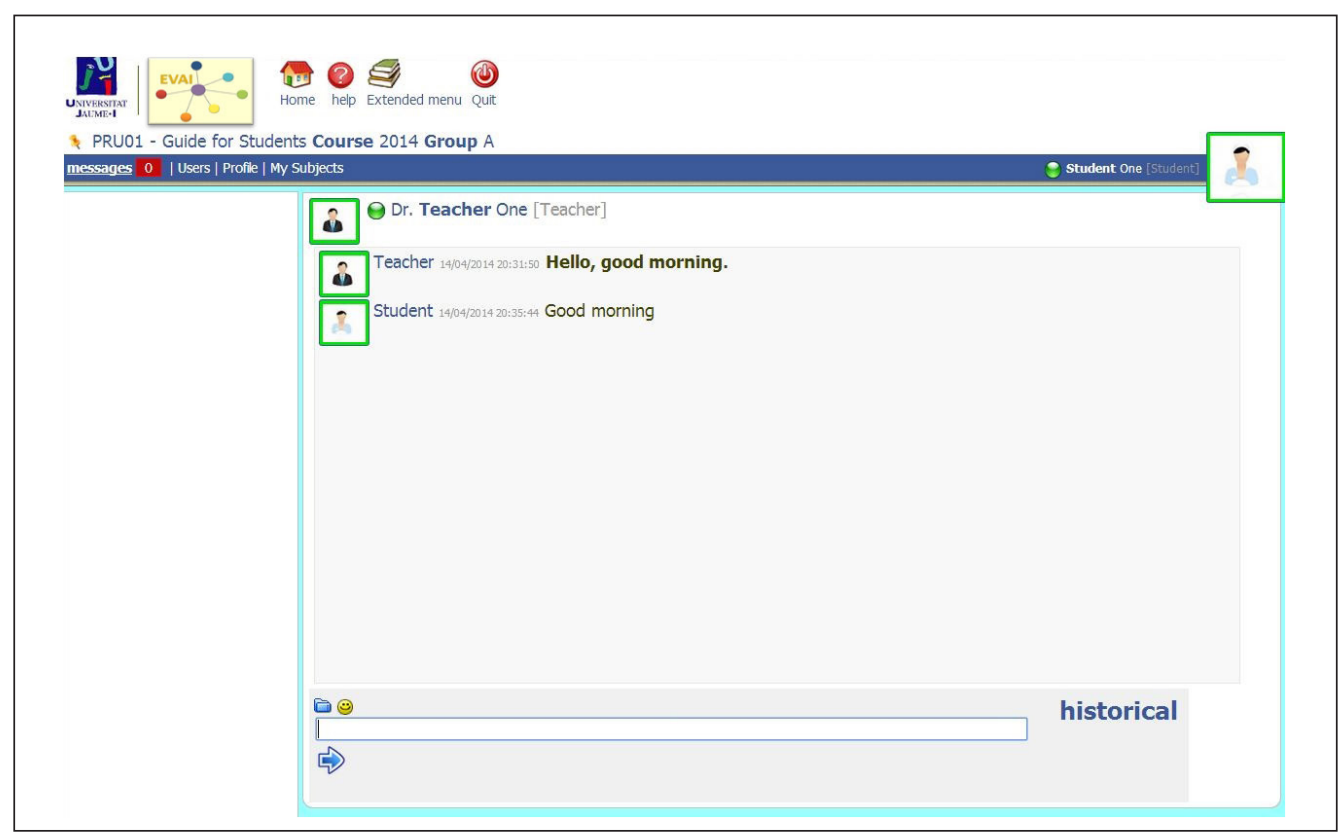

Figure 5b. EVAl-Messenger

We can also send attachments by selecting the icon that looks like a folder or insert an emoticon by clicking on the :-icon. Clicking on the word History allows us to consult all the conversations held with that person to date.

Once we have finished writing our reply, we can send it by pressing ENTER or clicking on the icon. In this way the virtual classroom can be used to hold a conversation.

If we have no unread messages and we wish to contact and send a message to a teacher or student, we can go to the Class photo gallery (Figure 6) and click on the photo of the person we want to send the message to.

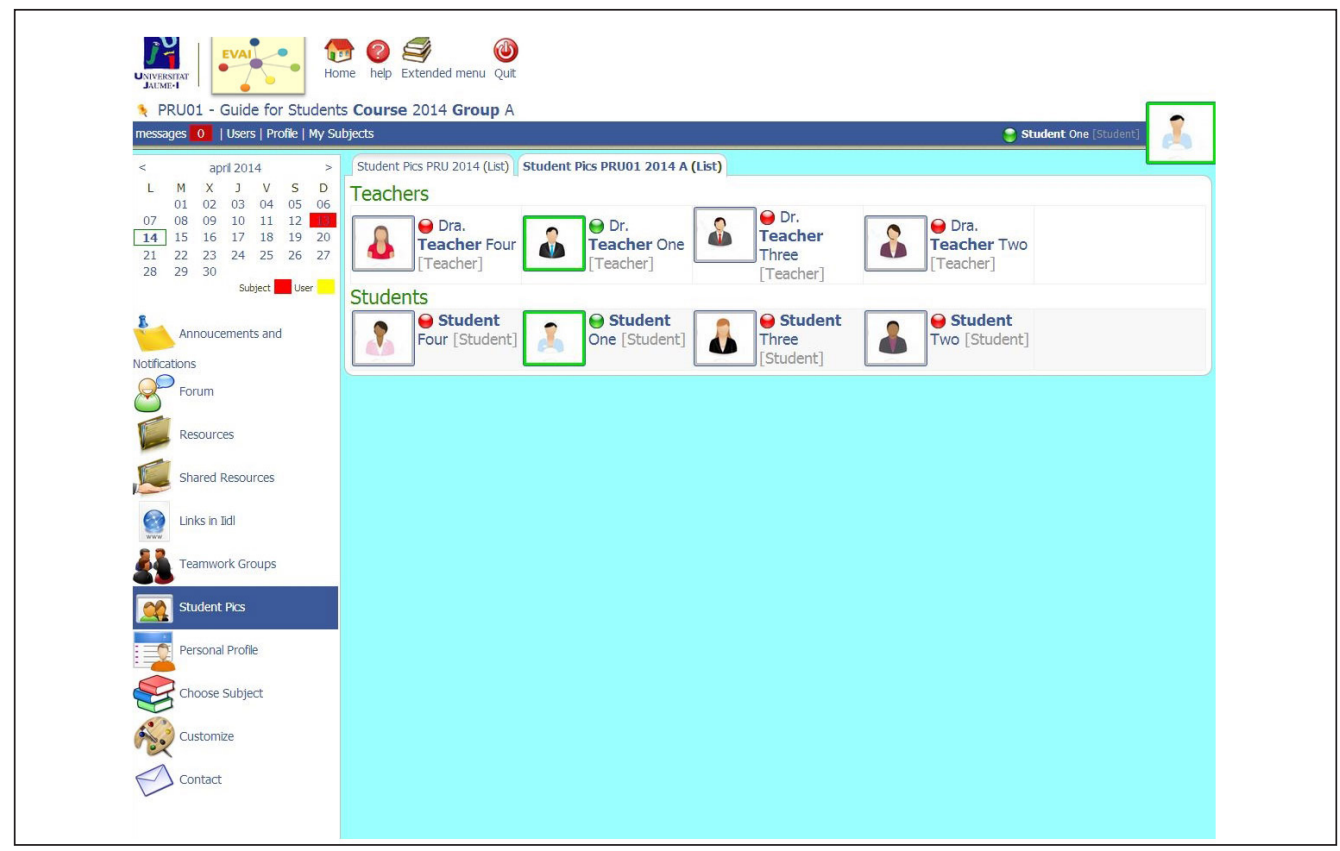

Figure 6. Class photo gallery 
This will take us to his or her personal homepage (Figure 7), where we will see a tab labelled Send messages.

Clicking on this tab will give us access to the space that allows us to send messages, which can be done in the same way as described earlier.

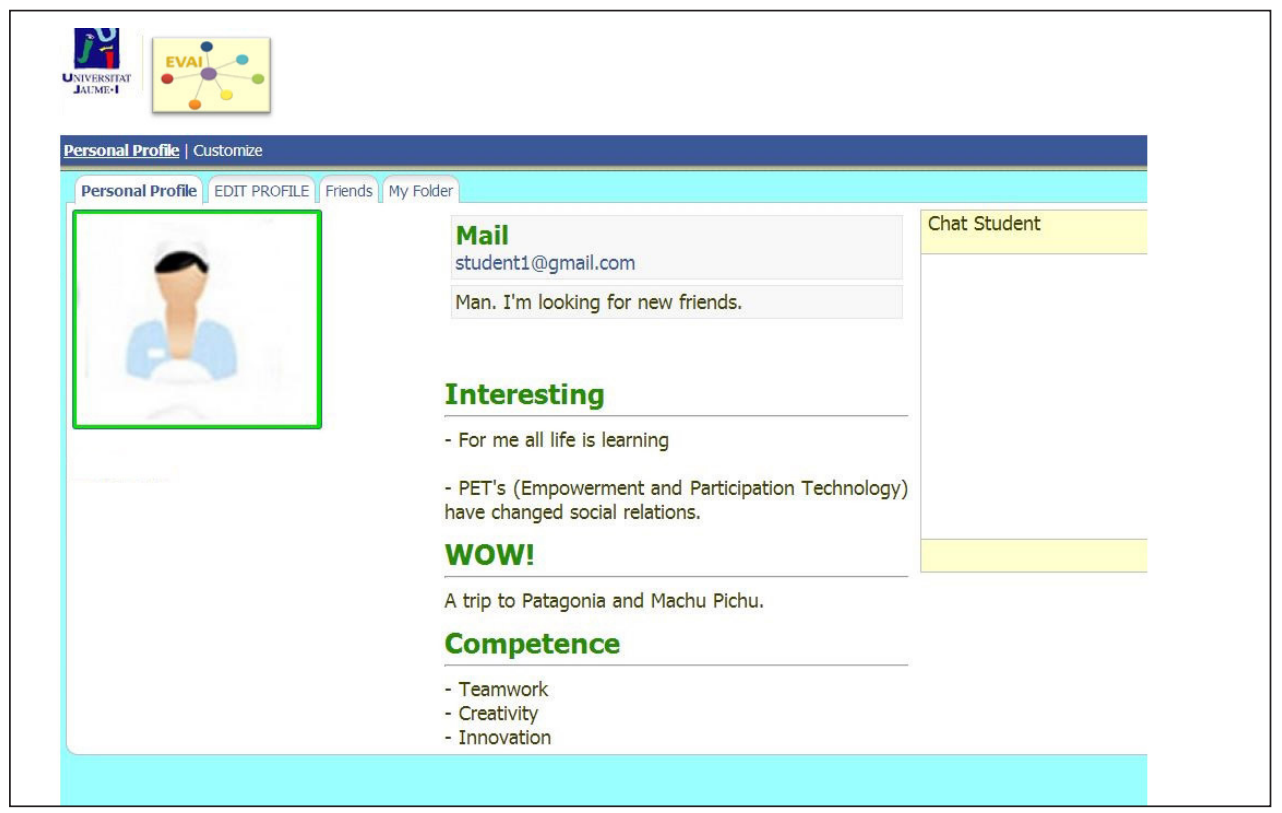

Figure 7. Personal student profile

\section{USERS}

This shows a list of the users who are currently online and connected (Figure 8).

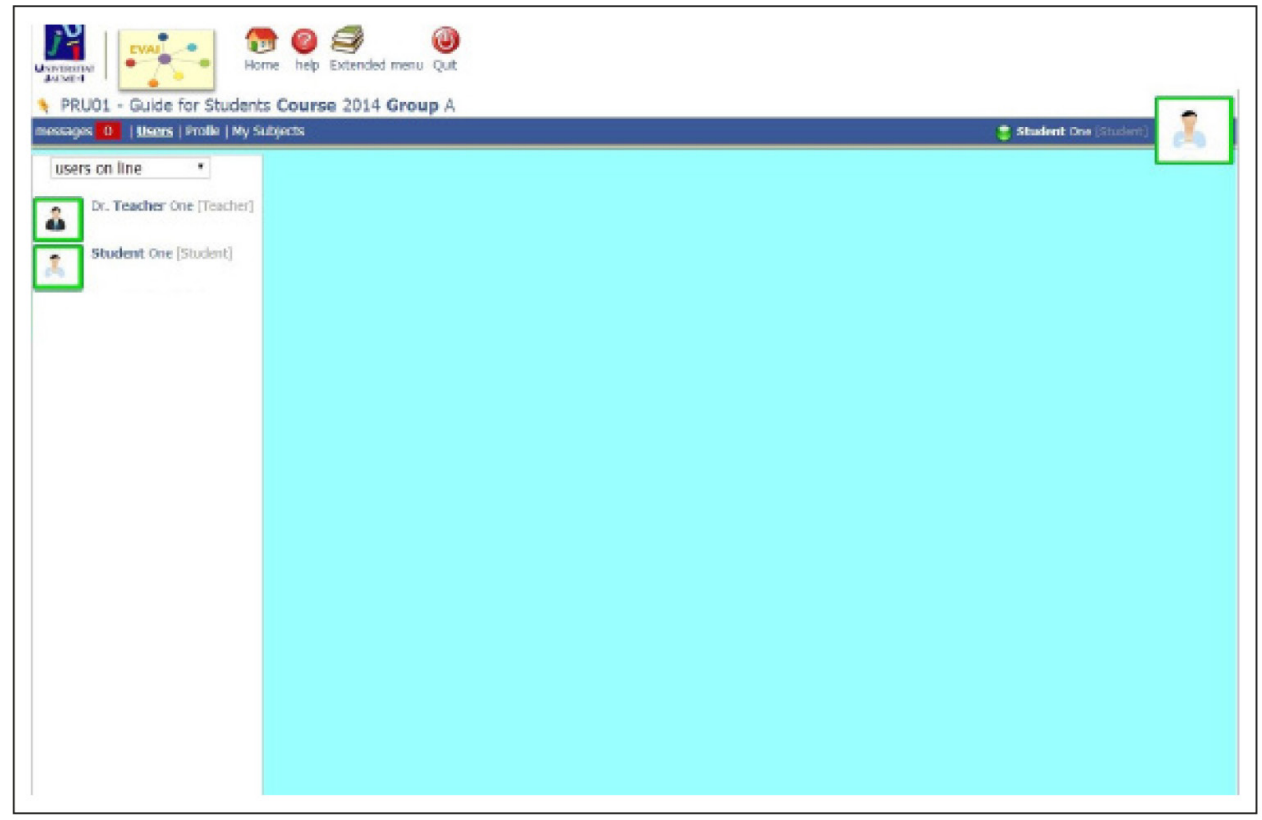

Figure 8. List of the online users 


\section{PROFILE}

This section provides access to our profile or personal homepage (see «personal homepage» section).

\section{MY SUBJECTS}

The My subjects section (Figure 9) shows all the subjects that are active for the user. Each of them can be accessed by clicking on the name of the subject.

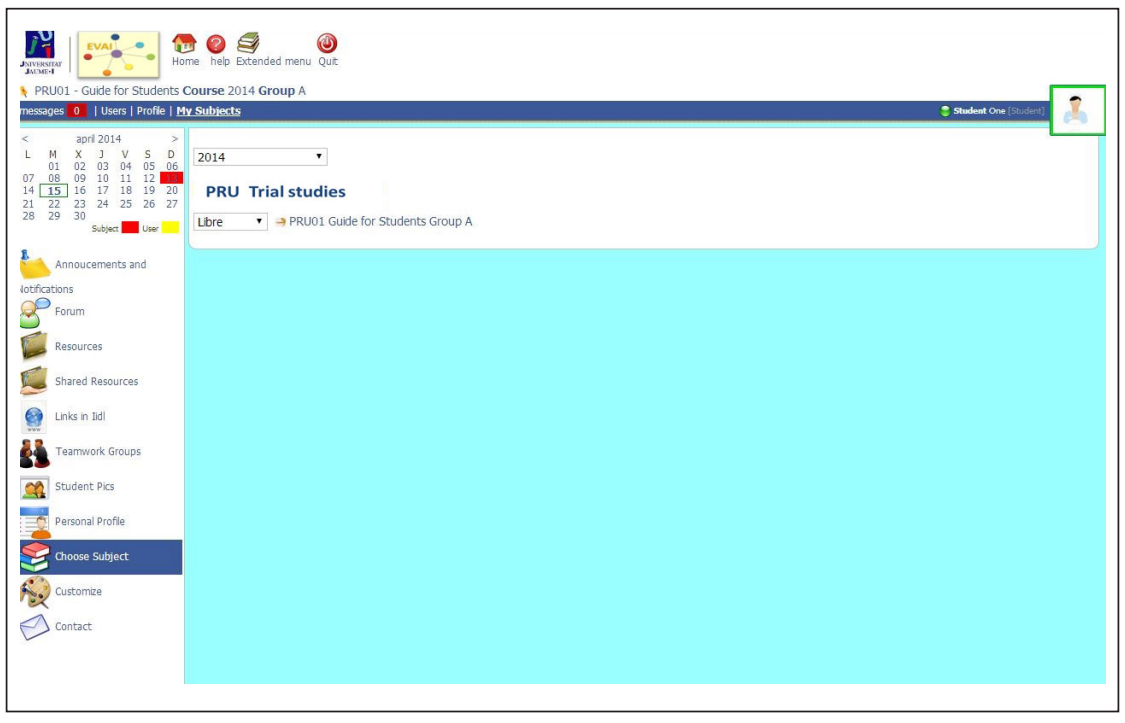

Figure 9. My subjects section

\section{3.}

\section{CENTRE SECTION}

In the centre of the screen we will find, first of all, the new users who have modified their profile recently (Figure I0).

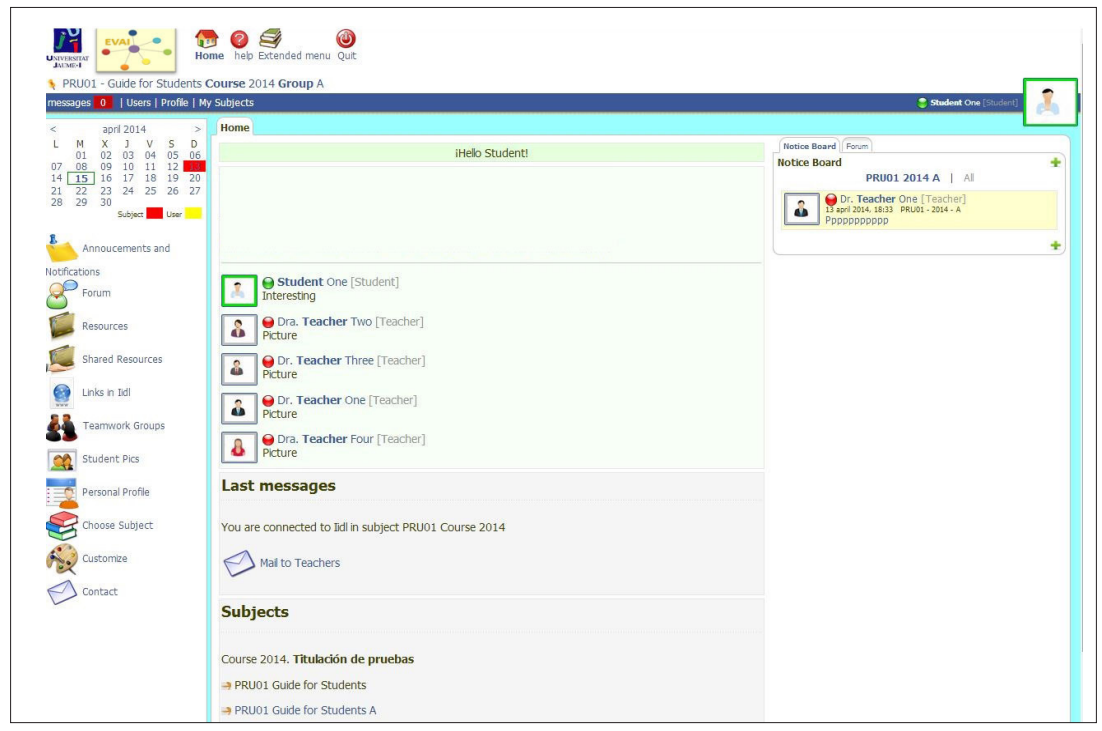

Figure 10. Centre section 
Below this list, we will find the Latest notices box, where the whole of the latest message is displayed. We can then see the subject in which we are connected (also shown at the top of the screen).

Below that, we can see a box called Subjects that shows all the subjects that make up the course and which is another way we can change subject, by clicking on the one we are interested in.

\section{4. \\ RIGHT-HAND PART}

On the right-hand side of the home screen we can see, firstly, the Notice board with the latest messages posted by the teachers and/or administrators; this may be limited to the subject we are currently viewing or, if we select «all», to those related to the whole course. Although only the name of the person who wrote the message and its subject will appear on the screen, the whole message can be accessed by clicking on the subject of the message (which will be described in more detail later on the paragraph Announcements and notices).

To the right of the notice board tab, we will see the box Forums, which displays a list of the latest messages in the active forums shown by the teacher in the subject we are connected to. Selecting the option «all» will display a list of the latest messages related to the course posted by users. Although only the name of the person who wrote the message and its subject will appear on the screen, the whole message can be accessed by clicking on the subject of the message.

\section{5.}

\section{SIDEBAR (LEFT)}

In the left sidebar (Figure II), we will find the following sections and subsections (which will be described in more detail later on the Forum paragraph):

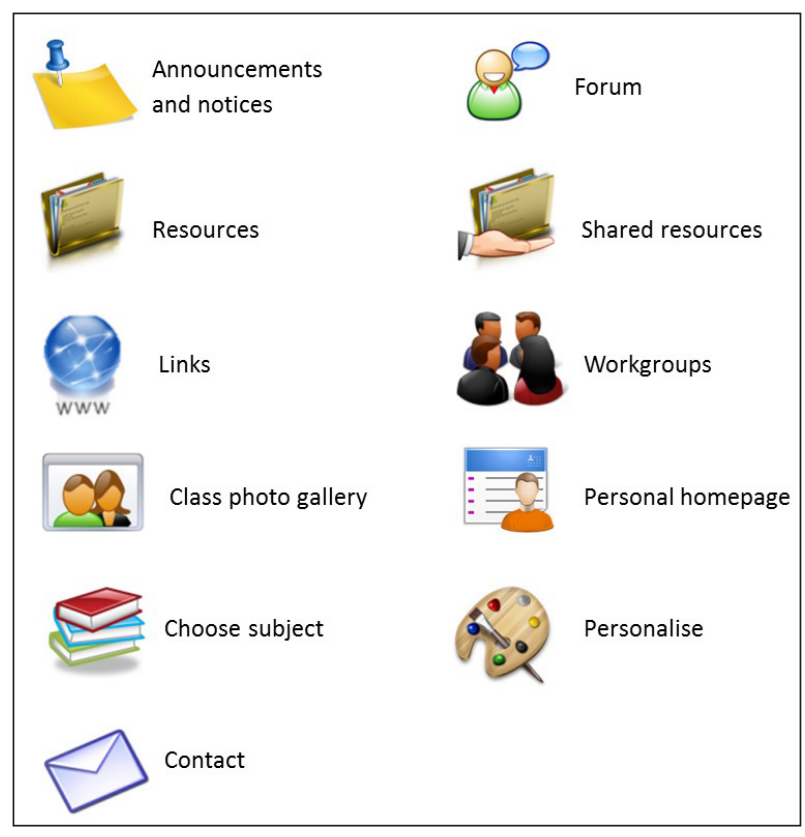




\section{ANNOUNCEMENTS AND NOTICES}

The Notice board (Figure 12) shows the messages of general interest posted by the teacher or the administrators; these are generally intended to provide information and no feedback is expected. Students cannot post messages on the notice board.

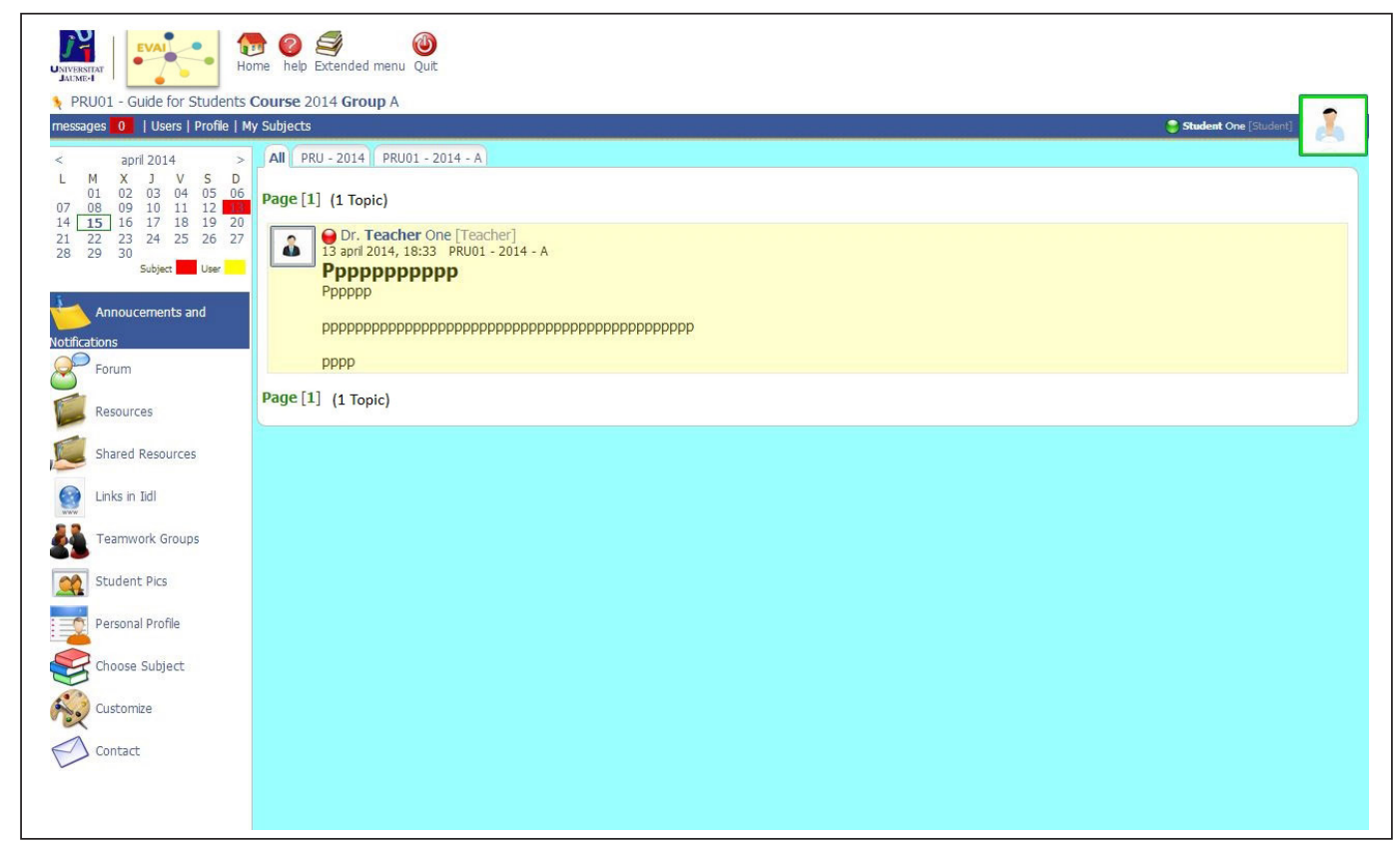

Figure 12. Notice board

\section{FORUM}

The forum (Figure 13) is one of the channels of communication used in the course to make e-learning easier, since it does not have to be done simultaneously.

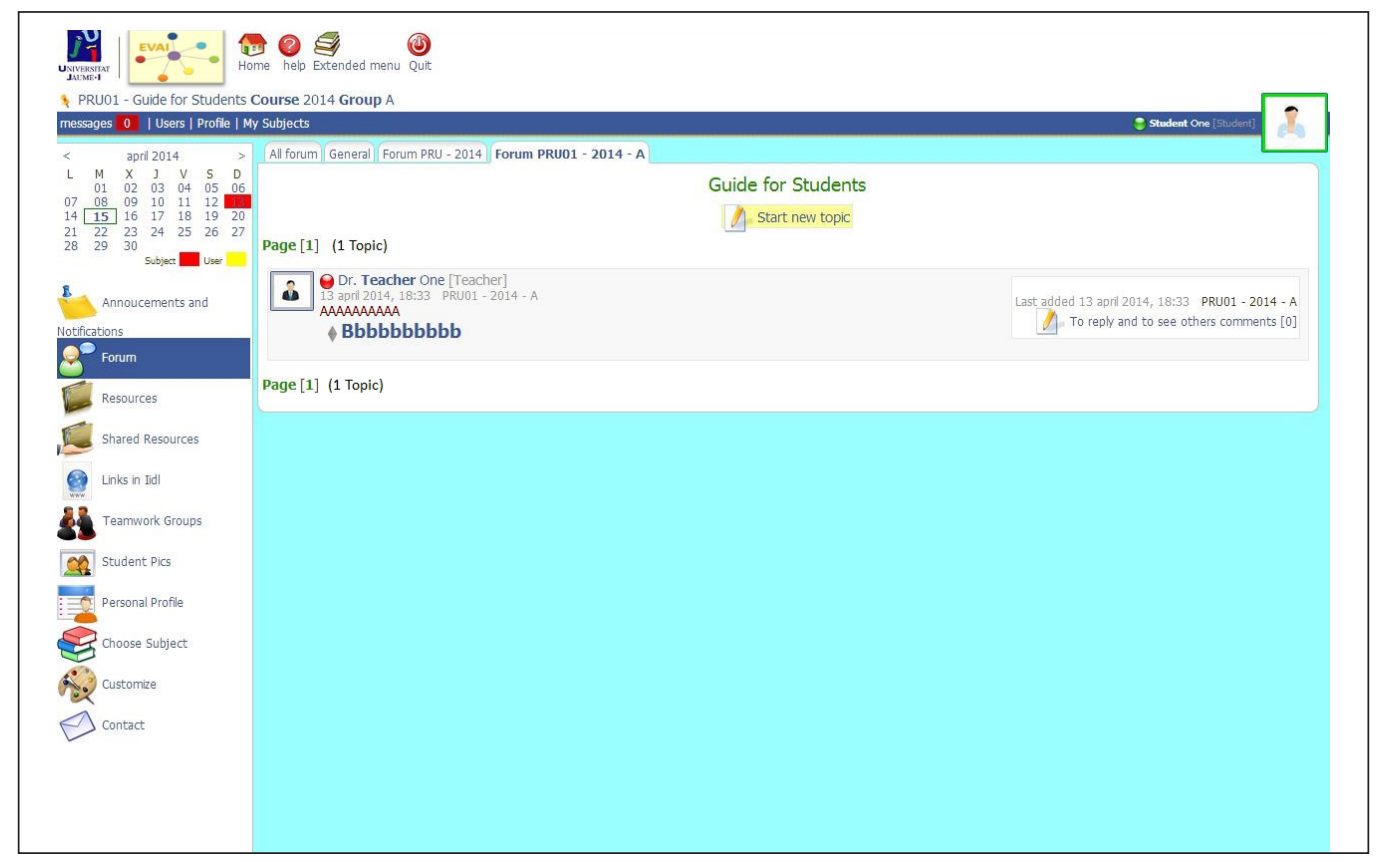

Figure 13. Forum 
To post a message in the forum, we must follow the steps below:

I. First, use the tabs to choose what section we want to link the message to. If the message is not strictly related to any subject or to the general functioning of the course, use the General forum. If the message refers to the general functioning of the course, the platform, etc., choose the Degree forum. If the message has to do with the subject we are in, then we select the forum for that subject.

2. Start a new thread. To do so, we must click on the Start a Thread icon / and fill in the subject and message fields, as well as again choosing the forum in which we want to post the new topic. The screen will show three fields to be filled in: Category, Topic and Comment (Figure 14). The field Category will tell us, in more general terms (e.g. information, subject assignment, programme, exercises, etc.), what the message is about. In the Topic field we must provide more specific information about what we want to post and, lastly, in the Comment field we write the full message to be added to the forum. Once the fields have been filled in, we click on Add.

3. Reply to a message in the Open forum. If we want to reply to a certain message or comment in a forum that is already open (Figure 15a, 15b), then we should click on the FORUM icon to bring up the list of open forums. We select the one we want and click on Add comments and see other replies, and a window will open for that forum with all its comments.

Following that, under the message that we have selected, we will see a space in which we can write our comment. When we have finished writing our comment, in order to post it, we must click on the button Comment.

However, direct access can also be gained through the Forums box, as was commented in the previous section «RIGHT-HAND PART».

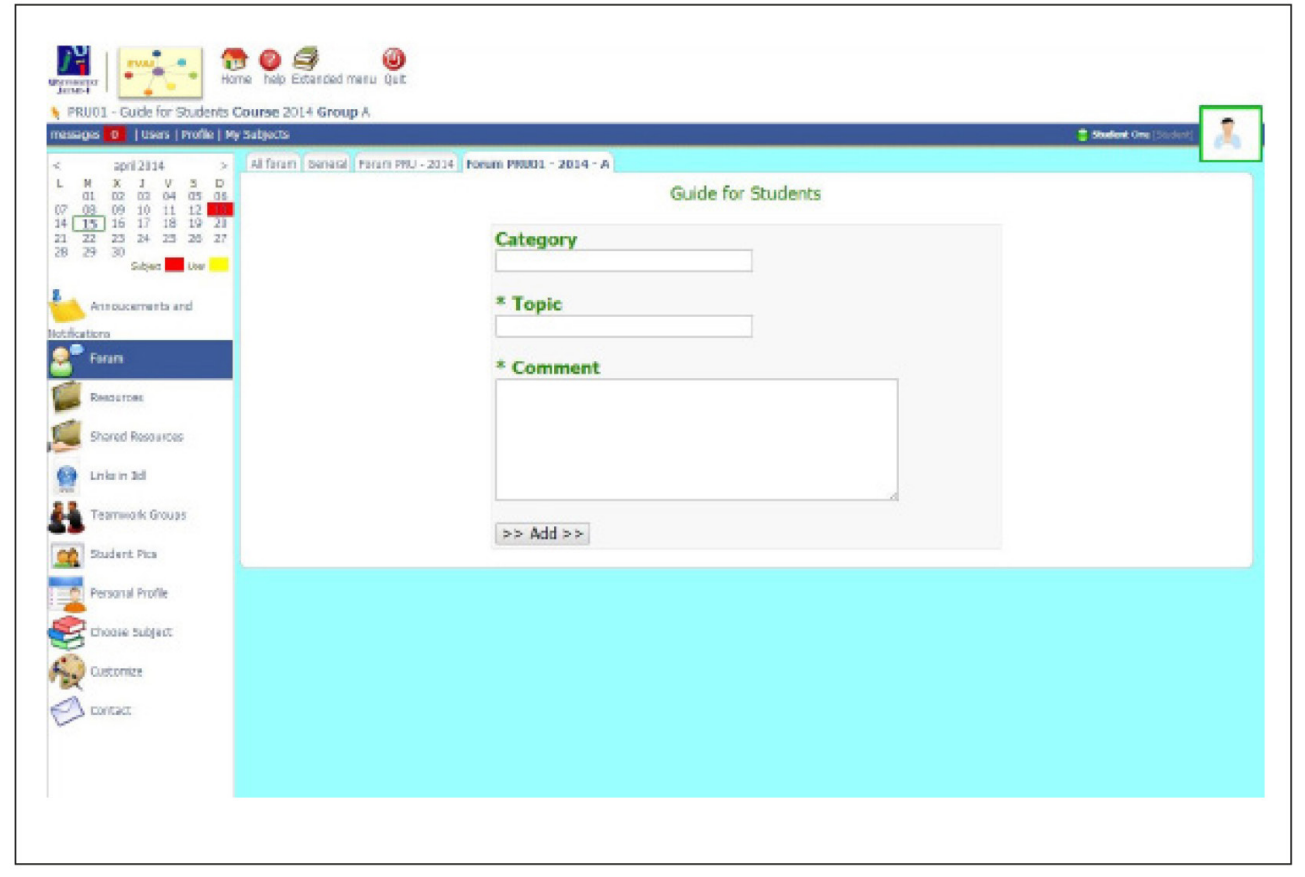

Figure 14. Forum: Start a new thread 


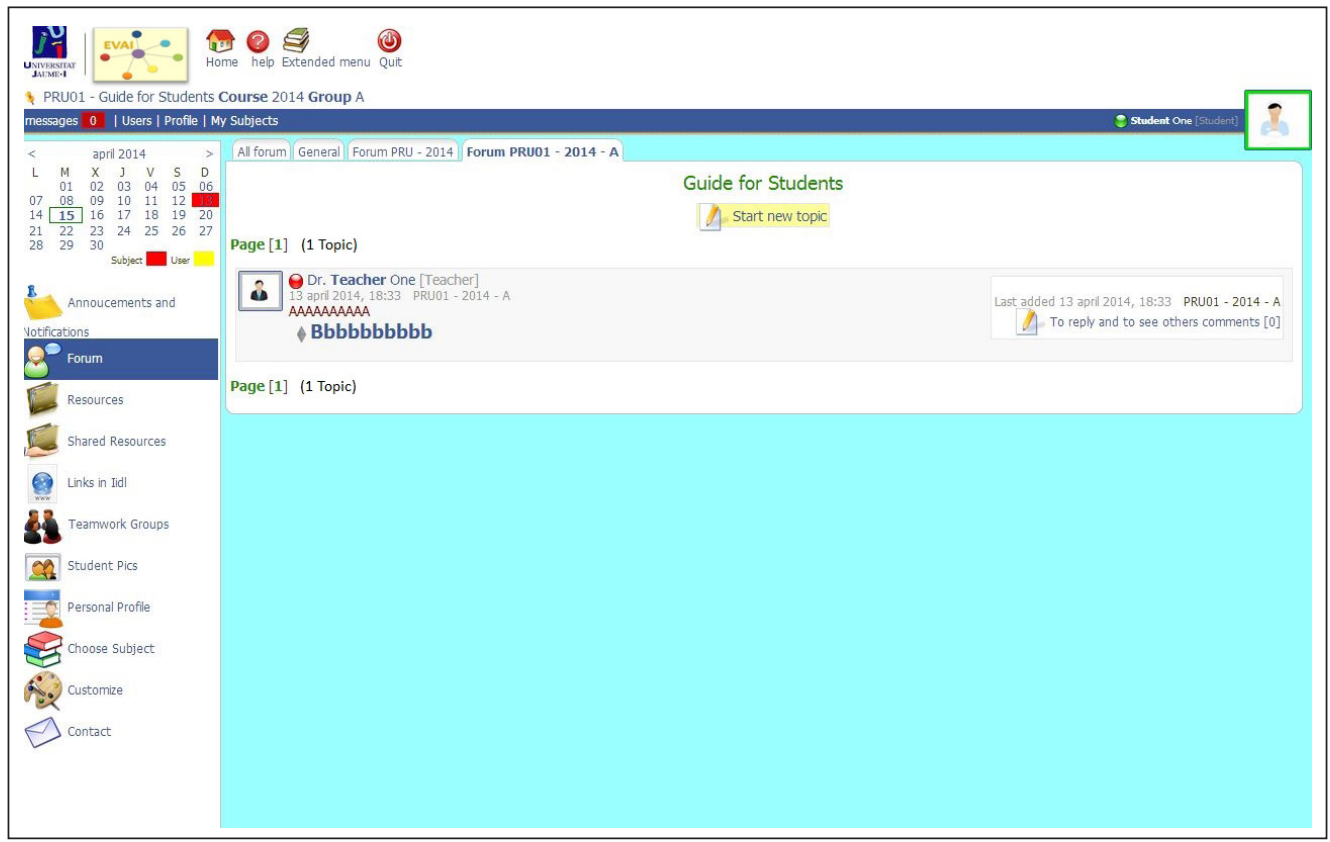

Figure 15a. Reply to a message in the Open forum

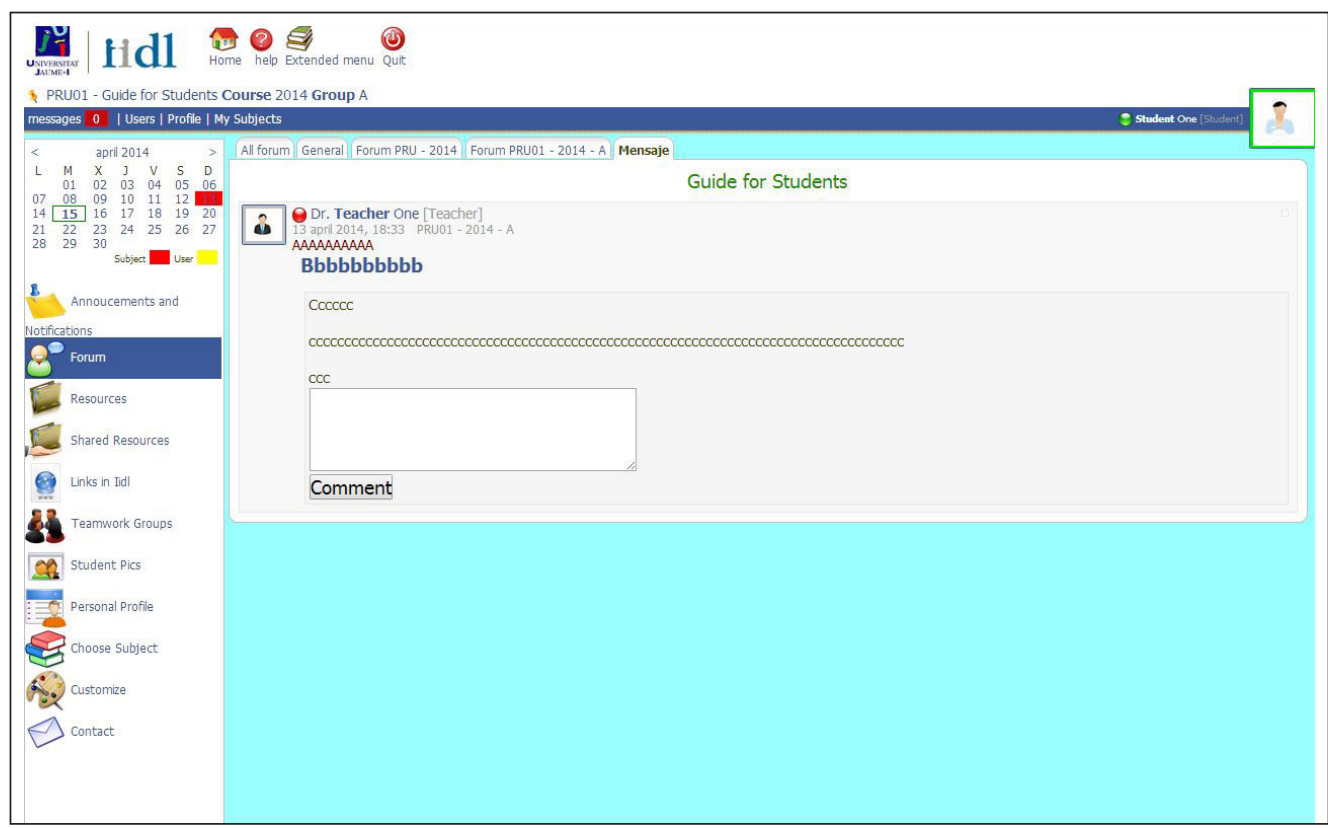

Figure 15b. Reply to a message in the Open forum

\section{RESOURCES}

The Resources space is the area within the platform from which we can access the assessment tasks (Figure 16), materials and activities that have been prepared by the lecturers of each of the subjects taught in the course. 


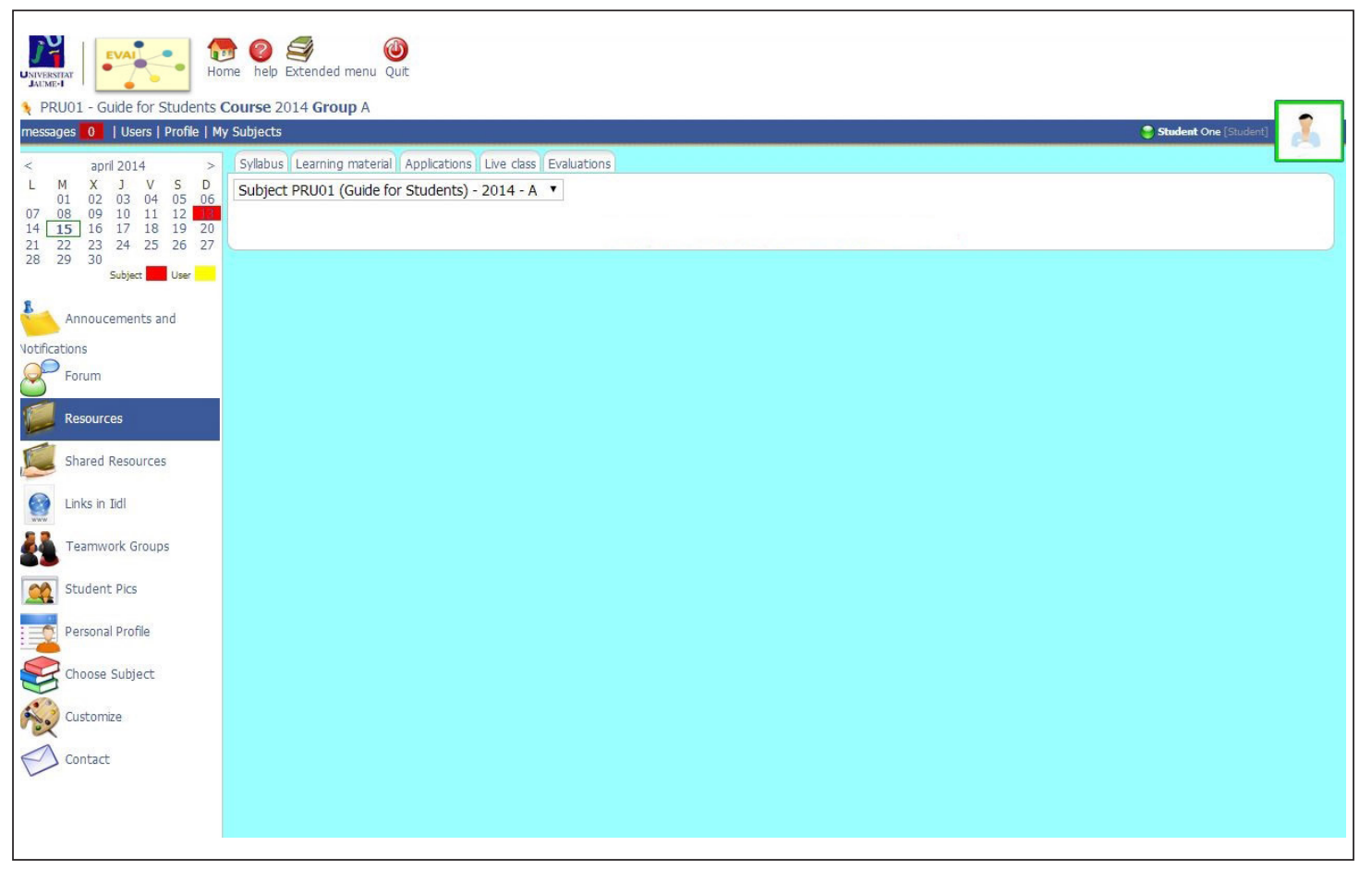

Figure 16. Resources

This section is made up of several subsections, the following standing out as being especially important for the teaching of the subjects:

- Teaching Material: in this subsection we will find and will be able to access the theoretical teaching materials, compulsory reading and other supporting resources created and posted by the teacher of the active subject to enable it to be taught (Figure 17). The tasks and activities for assessing the autonomous work of the students will also be posted in this same subsection.

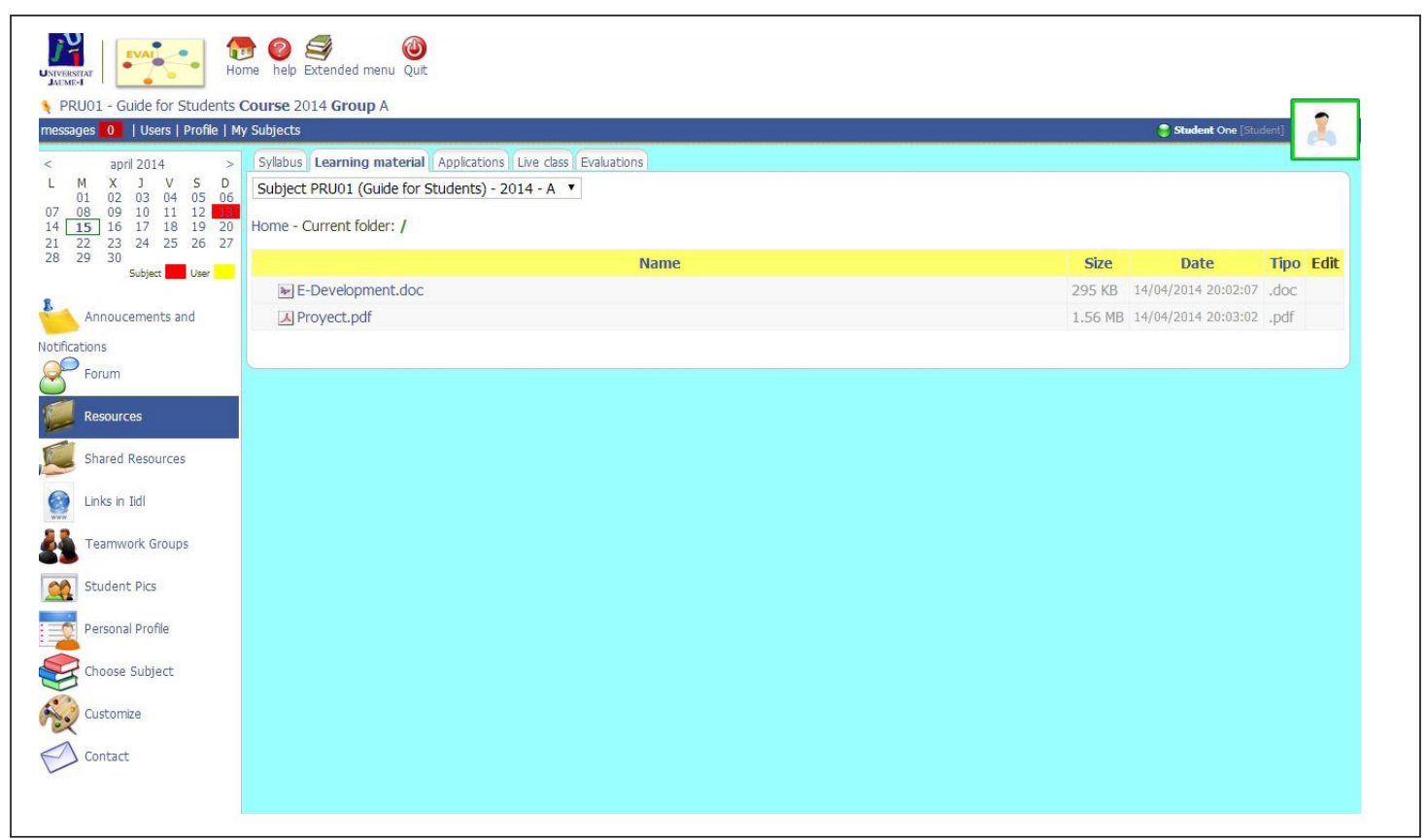

Figure 17. Teaching Material 
- Assessments: this subsection allows access to the questionnaires or multiple-choice assessment exams for the active subject currently in progress (Figure 18). When a student wishes to enter to fill in this questionnaire, he or she should select this tab, which opens another window beside the main one, in which the active questionnaire will appear. If the questionnaire is not active, a warning will appear.

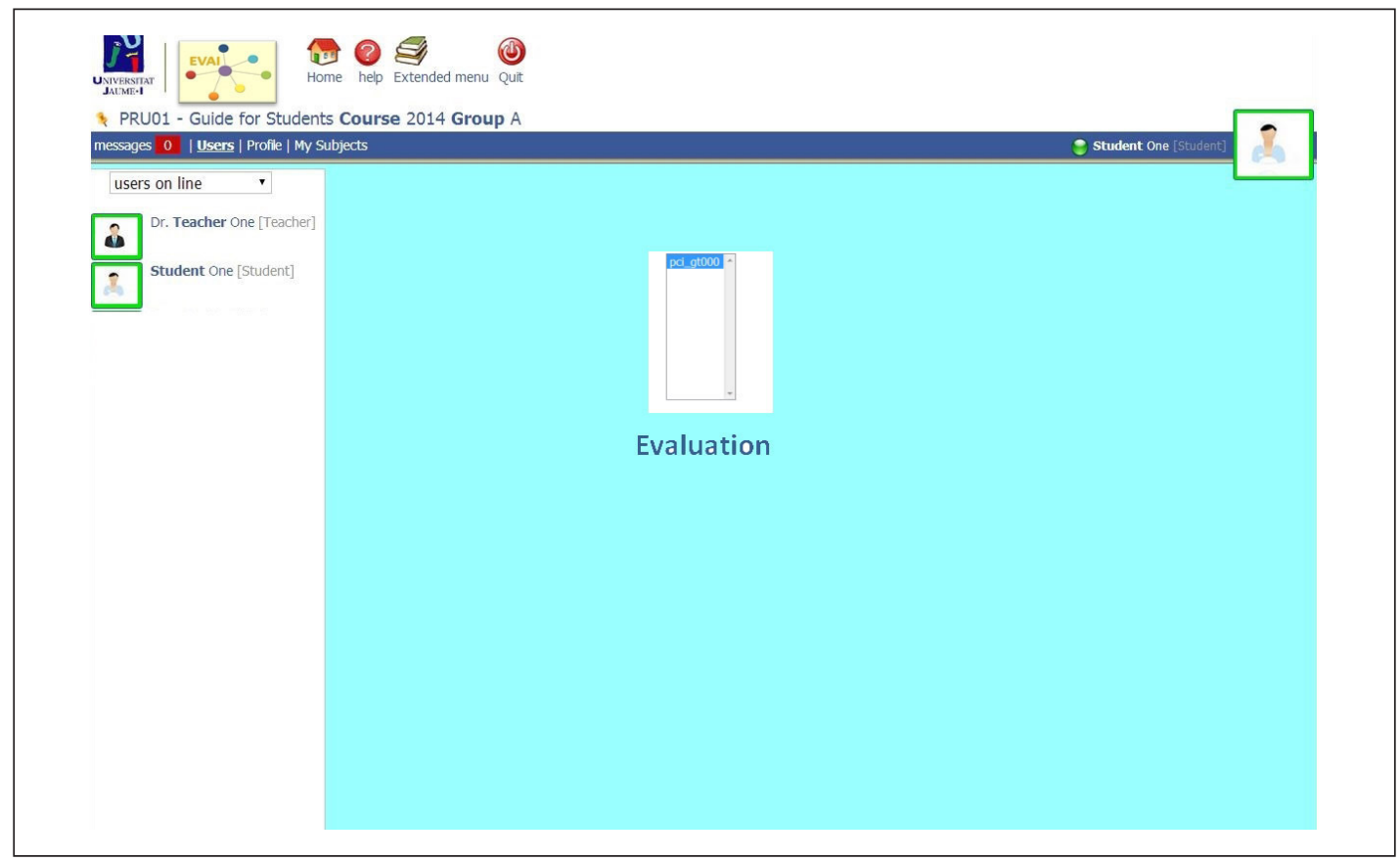

Figure 18. Assessments

To gain access to the questionnaire for the active subject, we should select the questionnaire in the central section and click on «perform assessment», which will open a window that allows access to it, while also displaying instructions on how to do it.

When going to perform a questionnaire it must be borne in mind that access may be limited (it can only be accessed once), as may the time available to answer it, and therefore the student must ensure that everything is ready (including the technical conditions) before beginning to answer it.

\section{SHARED RESOURCES}

The subsection Shared resources allows any file or document that may be of interest for the course to be uploaded to the platform, so as to make it available to all members of the teaching staff and students.

Shared resources can be consulted by simply accessing them through the Shared resources menu (Figure 19). This can be used to list all the resources of the subject or to carry out a search based on one of the following criteria: Posted by (allows a search based on the name of the user who uploaded the resource or resources), Profile (allows searches based on the name of the resource), Description, Type (for the time being, searches can only be made for websites, images, audio and video files).

Resources can be uploaded by means of the Add tab (Figure 20). Before uploading the file, we must select the section or subject we want to assign it to on the drop-down menu, so as to allow bet- 


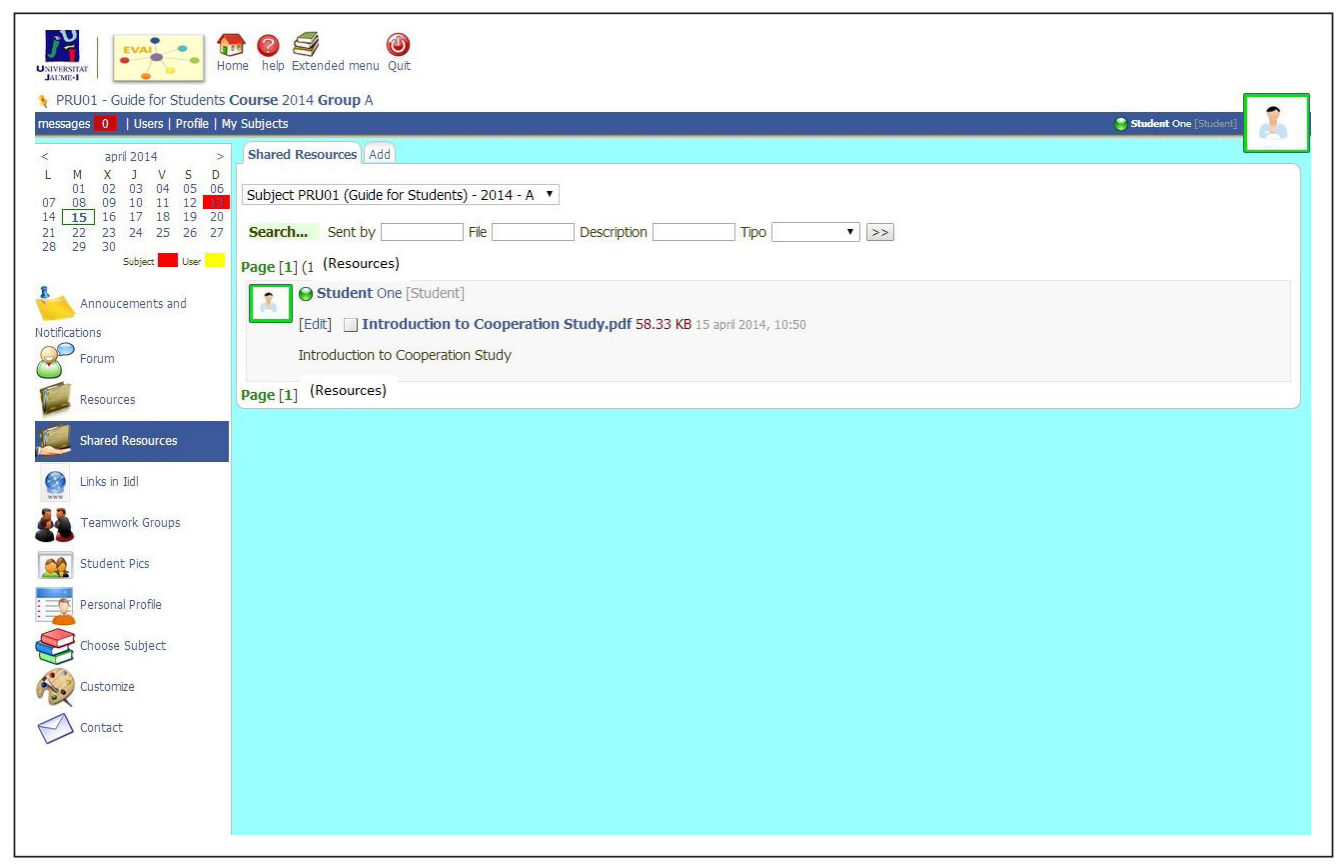

Figure 19. Shared resources

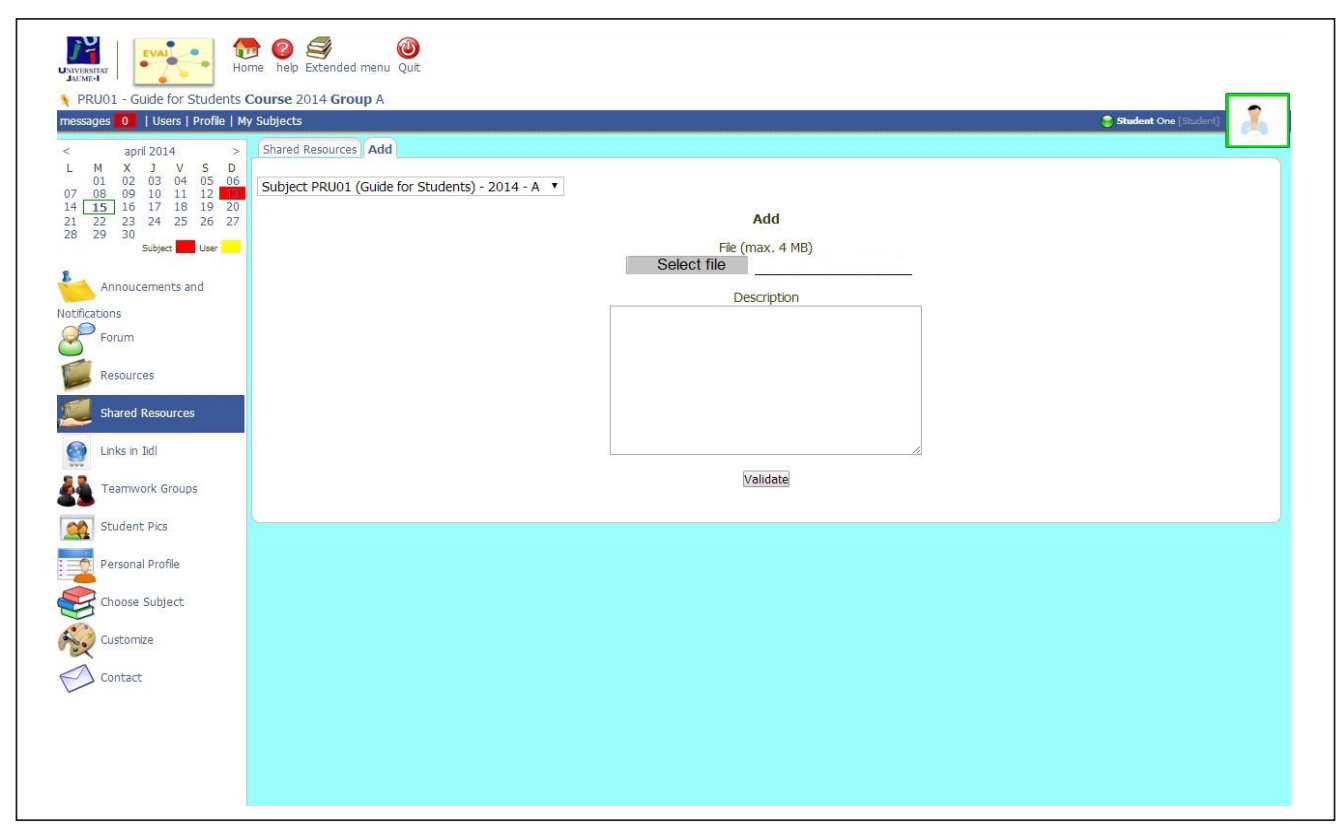

Figure 20. Add to Shared Resources

ter organisation of the resources. If we consider it appropriate to do so, we can introduce a short description of the file that we are going to upload.

\section{LINKS}

The purpose of the subsection Links is similar to that of Shared resources, but in this case refers to Internet contents that may be of interest to others taking the subject. Both links to a website and links to a file, which must be attached, can be included. 
It has two tabs, one containing a list of the links that are currently available and one that allows new links to be added. The Links tab allows the user to conduct searches based on different criteria: Area (refers to the code number of the subject), Key (key word or words), Degree and Website (address of the associated link). Moreover, the list of links can be filtered according to two criteria: Latest and Highest rated (Figure 2I).

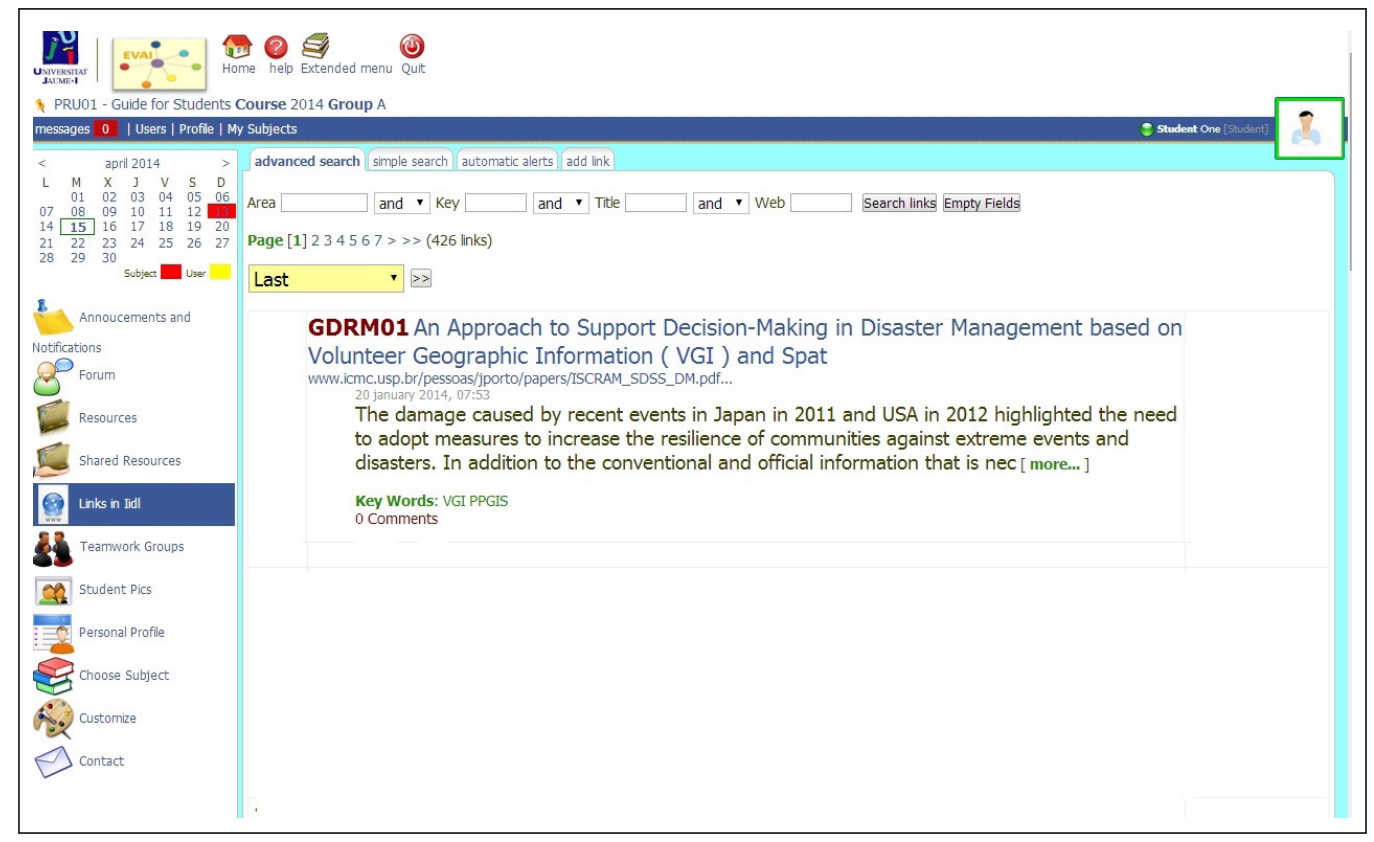

Figure 21. Links

The Add link tab provides the tools needed to use a series of different search engines (Google, Yahoo, Altavista and Lycos) to conduct a search for Internet content, which can later be posted on the platform together with all the information that we deem necessary (degree, key words, description) (Figure 22).

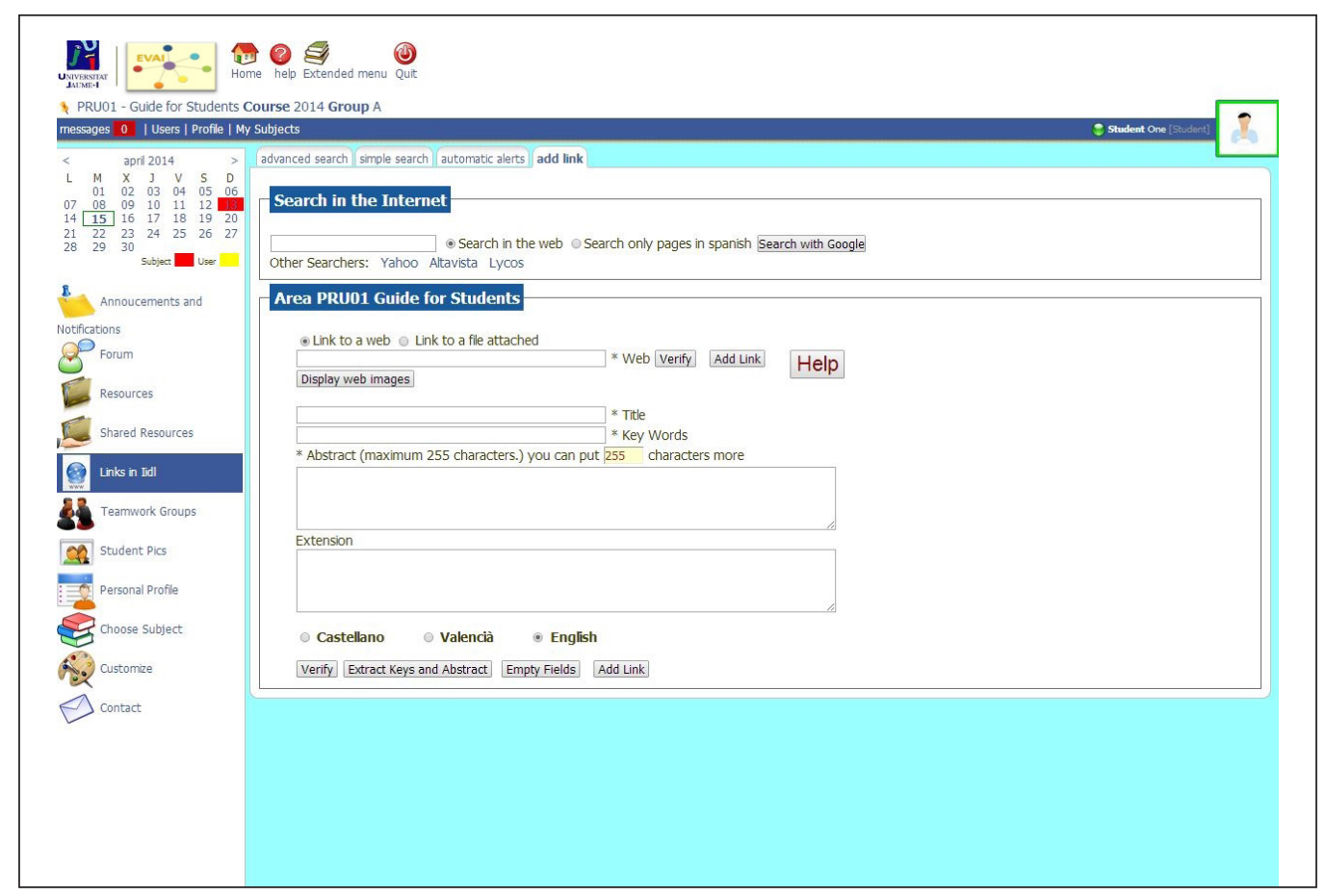

Figure 22. Add Link 
We can get help about the procedure for adding new links whenever we needed by clicking on the Help (Figure 23) in the top part of the active tab (Add link). This will bring up a brief description in the upper part of the screen.

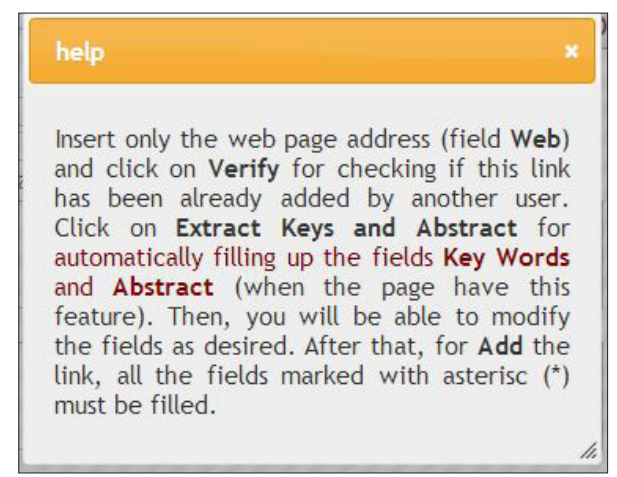

Figure 23. Help dialog box

It is important to bear in mind that before adding a new link we must check that it has not already been included in the platform by clicking on the Check button.

\section{WORKGROUPS}

This subsection is where we can create and manage workgroups, which both the students and the teachers of a subject are free to join. The group's password will appear beside the name of the group.

This screen has five tabs:

- Groups. This shows all the groups that have been set up for the active subject (Figure 24).

- My groups. This only shows the workgroups the user belongs to (Figure 25).

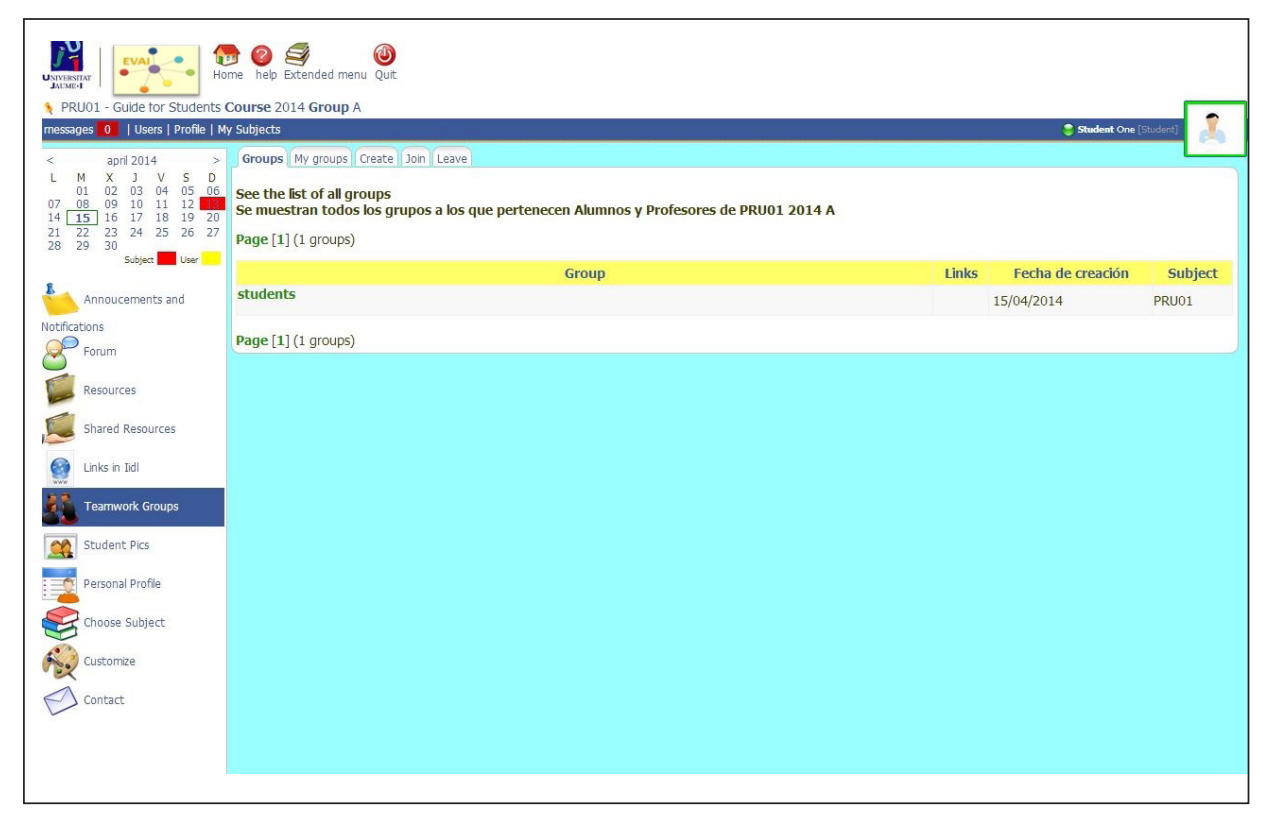

Figure 24. Groups 


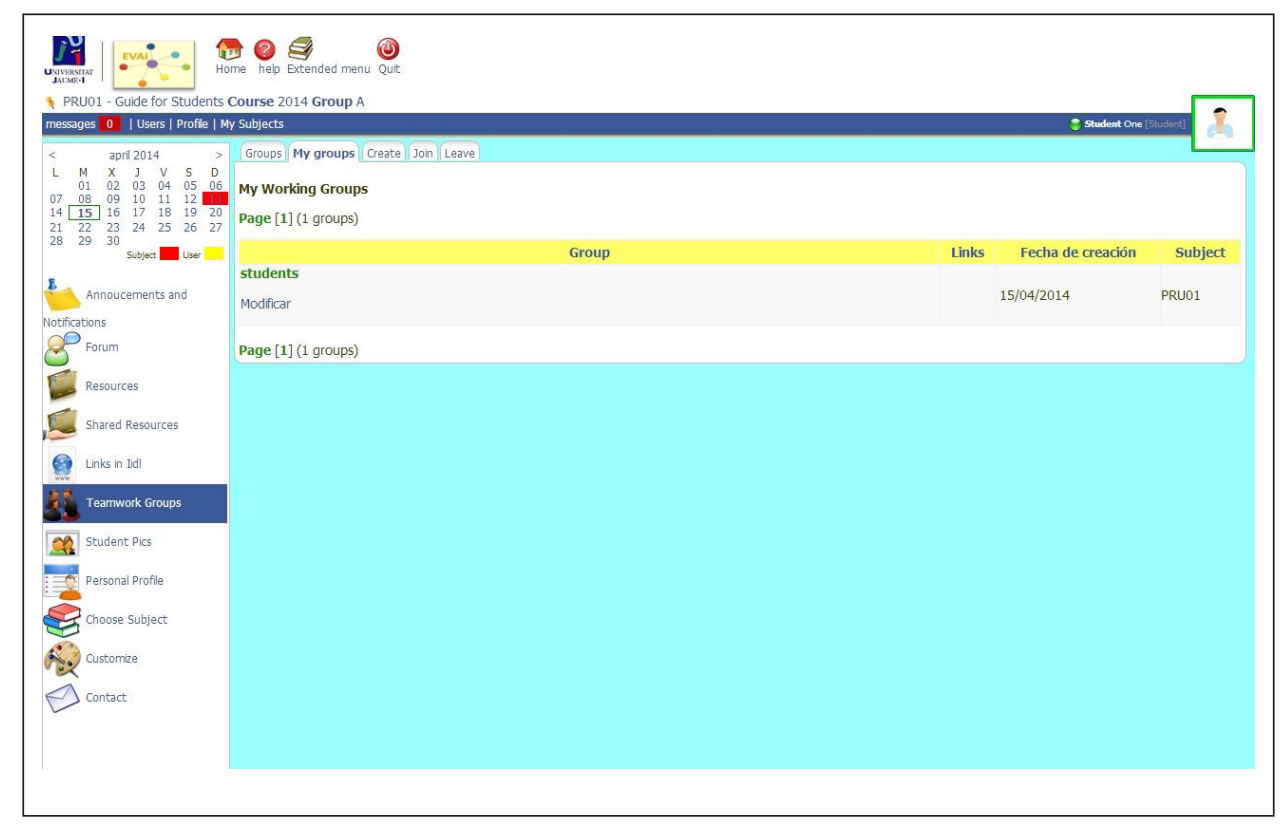

Figure 25. My Groups

- Create. This allows a new workgroup to be set up (Figure 26). One of the students, the first of them, is the creator giving it a name and a password. Right after the creator will give this name and password to the rest of the members for them to join the group.

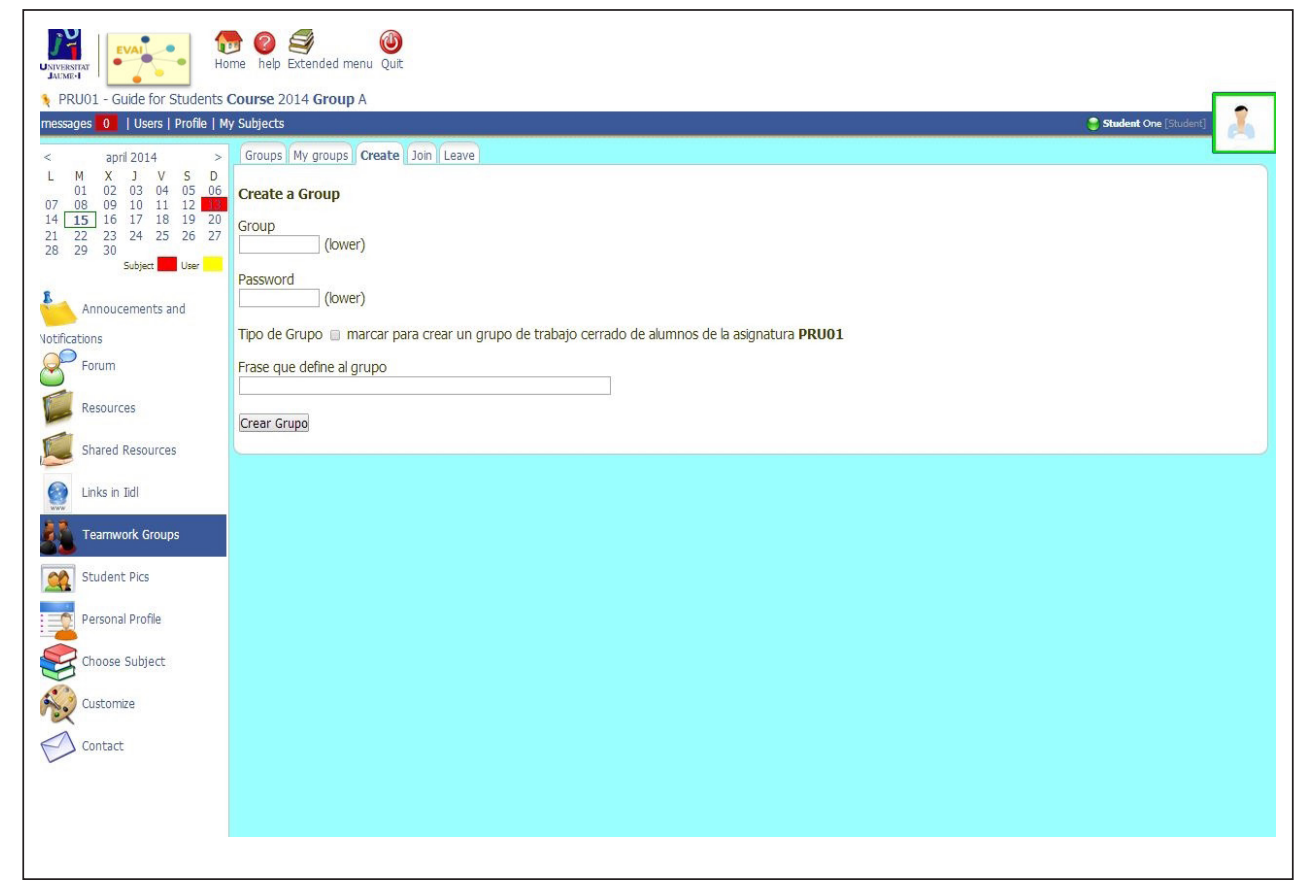

Figure 26. Create group

- Join. This allows the student to join one of the existing workgroups whe he knows the name of the group and the password he or she has been given by the creator of the group (Figure 27).

- Leave. This allows the user to unregister from any of the groups he or she belongs to, by stating the name of the group (Figure 28). 


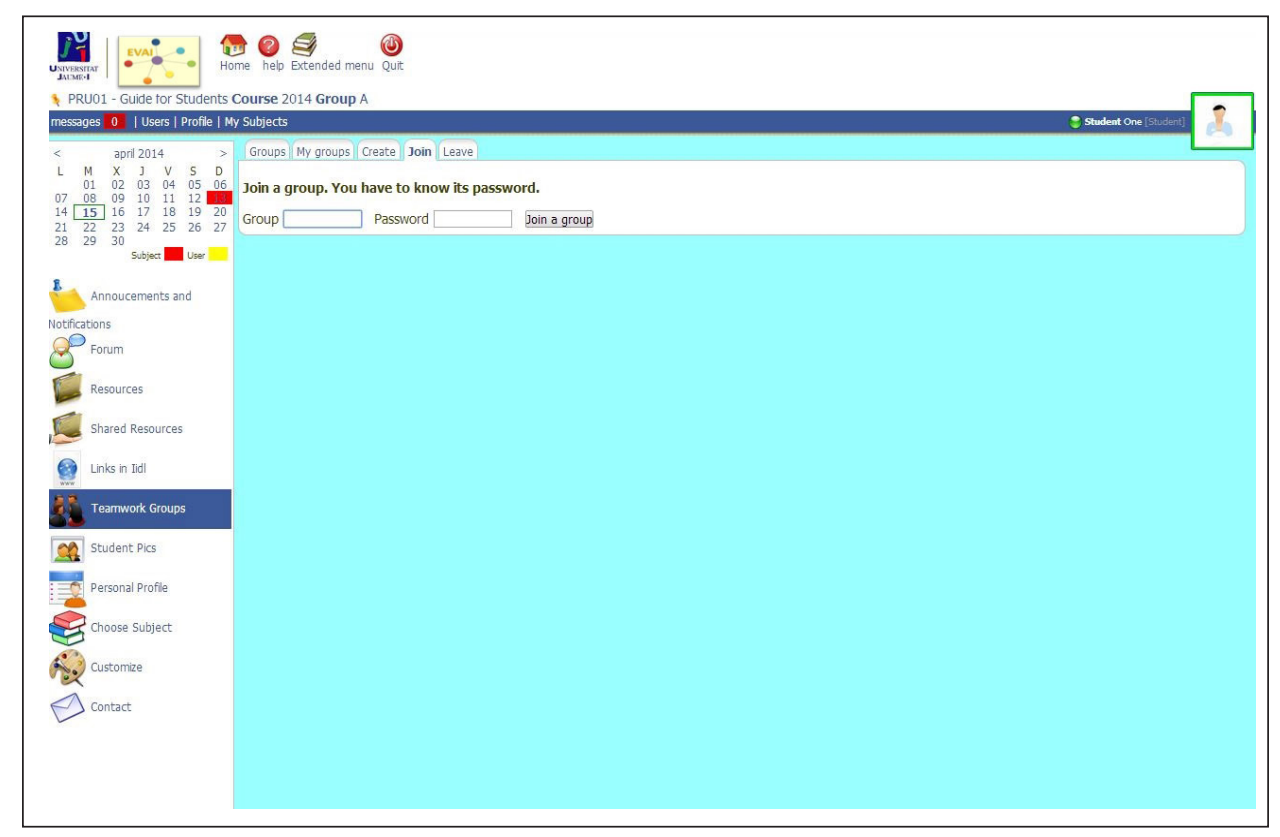

Figure 27. Join the group

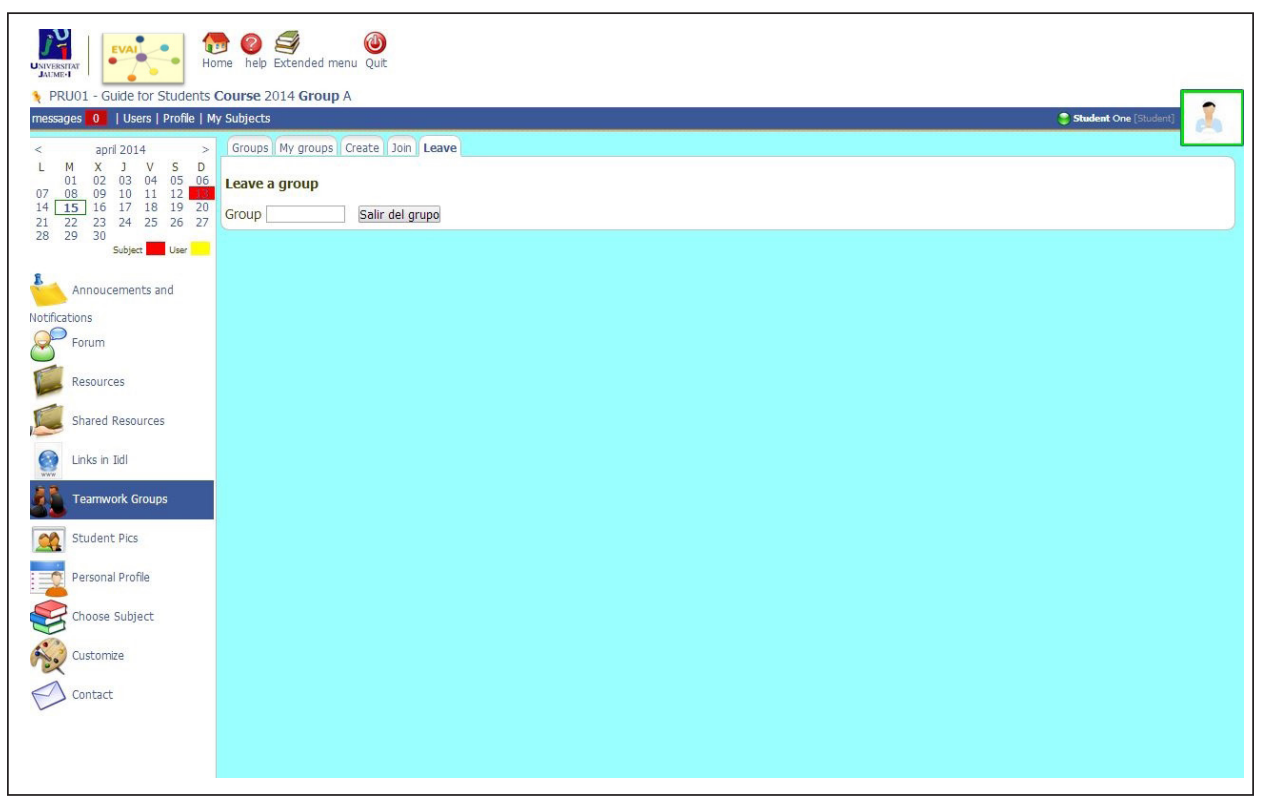

Figure 28. Leave the group

Each workgroup has its own space which contains the names of the members, the group forum where they can discuss and debate relevant issues, and a folder where files can be uploaded and shared.

\section{CLASS PHOTO GALLERY}

The photo gallery lists all the students and the members of the teaching staff involved in the subject we currently find ourselves in (Figure 29).

Clicking on any of the names or photos grants direct access to the corresponding personal homepage, where we can obtain that person's contact data or access the EVAI-Messenger area to send that person messages. 


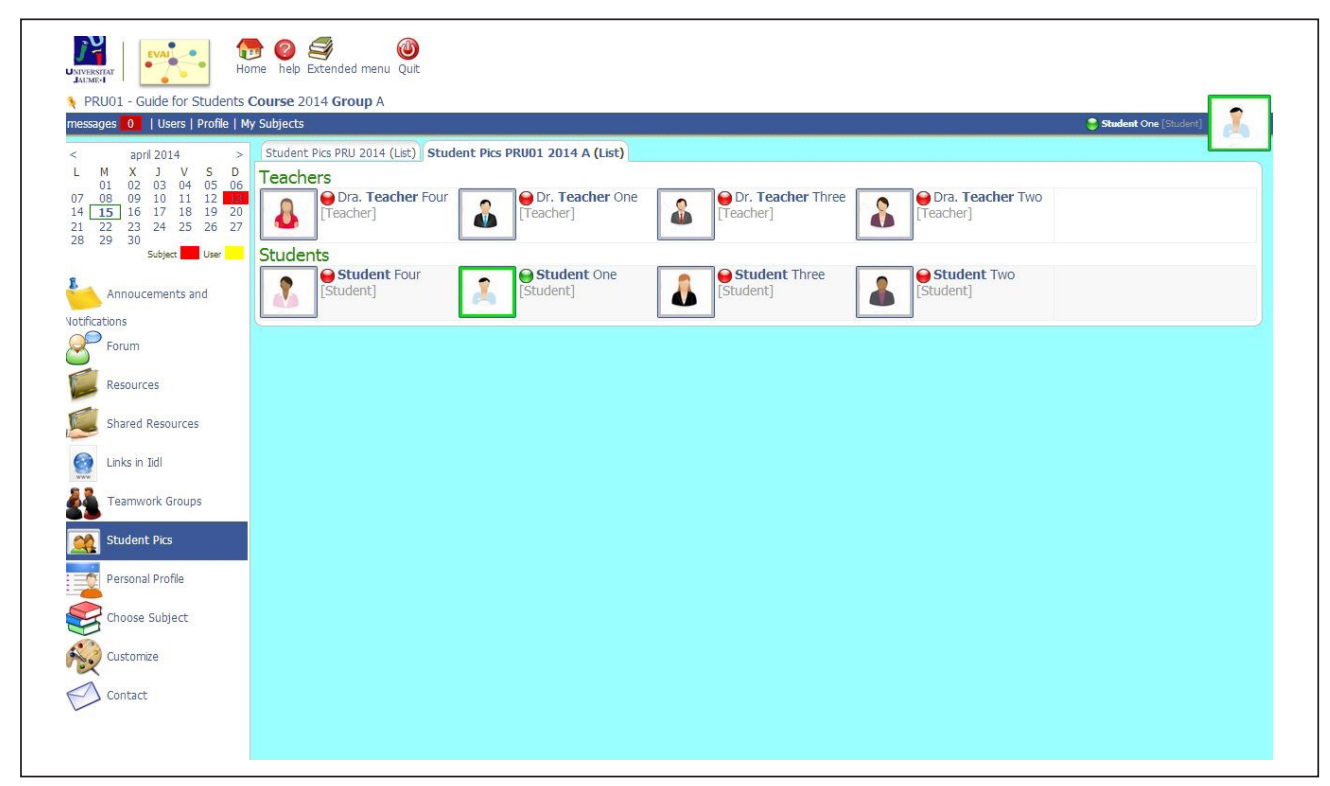

Figure 29. Photo gallery list

\section{PERSONAL HOMEPAGE}

The personal homepage consists in a record showing the user's personal details. Clicking there opens up another window next to the main screen, which has three tabs:

- Personal homepage. This includes all the information that the user has provided about him or herself, although the only details that will be available to the other users are those that were chosen on setting up the profile (Figure 30).

- Edit profile. This allows the user to fill in/modify/delete his or her personal details, such as basic data, photo, videos, social networks, change password, etc. (Figure 3I).

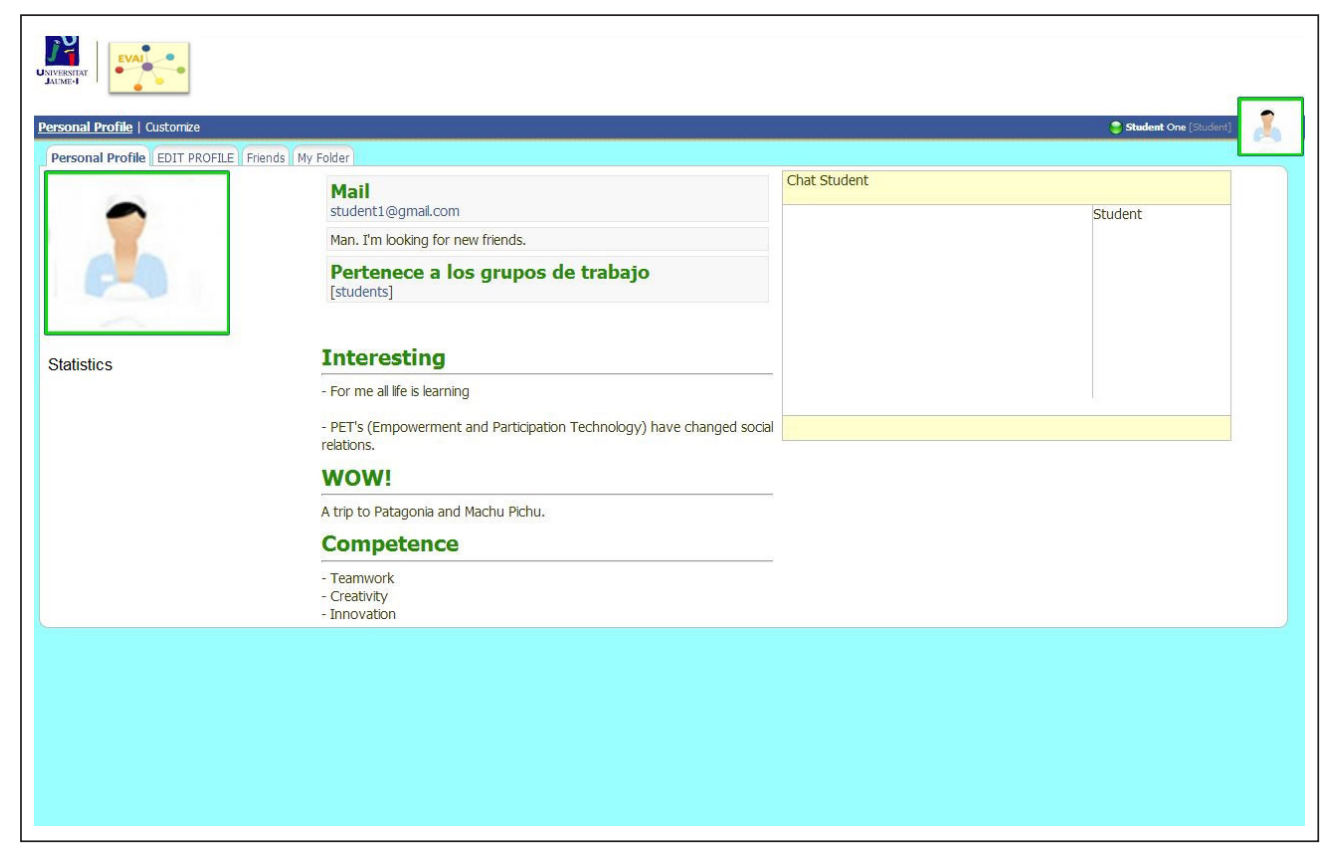

Figure 30. Personal homepage 


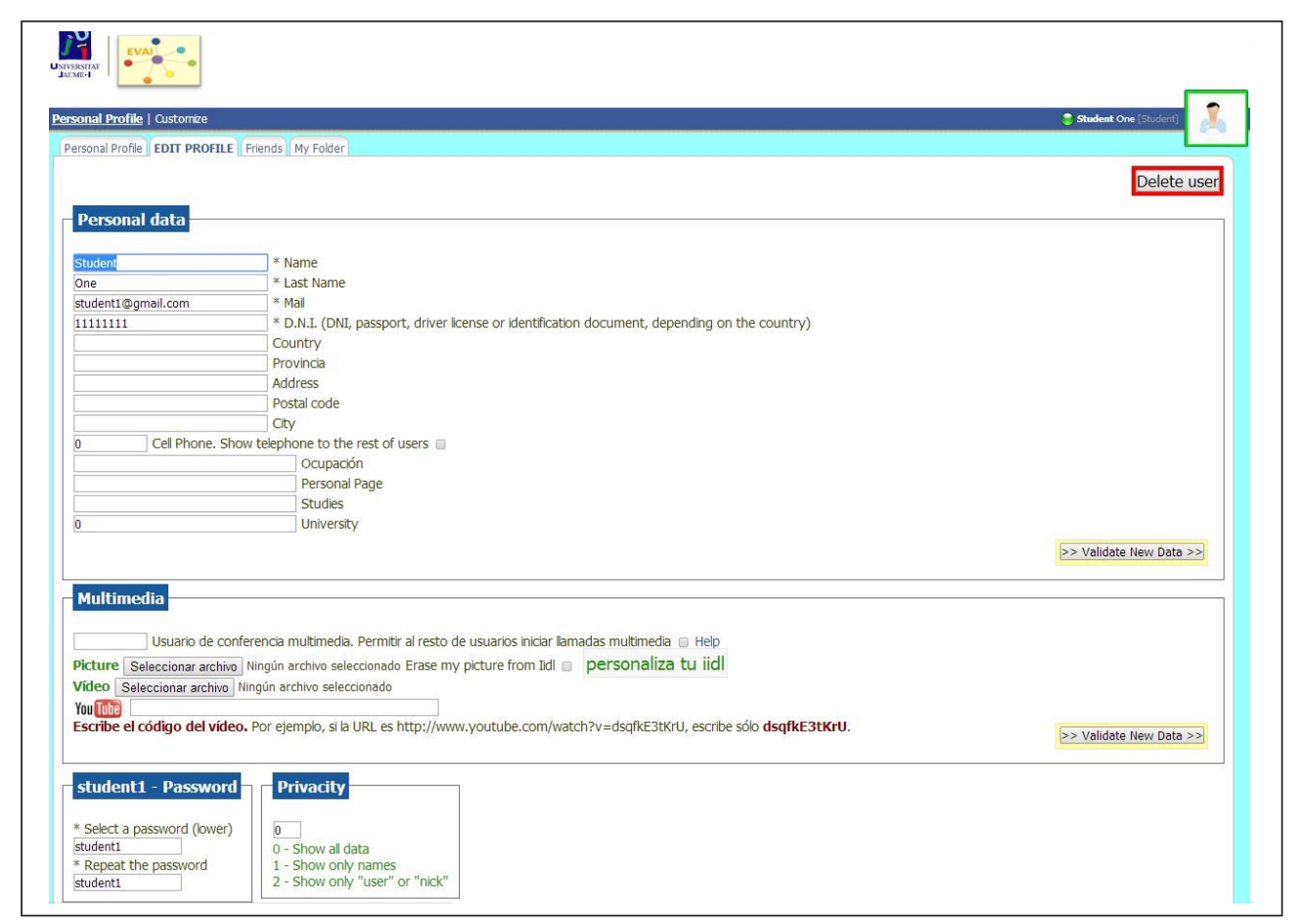

Figure 31. Edit profile

- Privacy level: the student can choose among three levels:

$0=$ Show all data.

$\mathrm{I}=$ Show only his or her name and surname.

$2=$ Show only the user's name.

It should be noted that, on making any kind of change to any of the fields of the profile, the user must validate the new data by clicking on the button [validate new data] and updating the page.

- My folder. This area is where students can upload their assignments for each subject. It works in a similar way to attaching a file to an email. It contains a folder called «Teacher» and clicking on it brings up a series of subfolders, one for each subject (Figure 32). All the assignments and tasks set

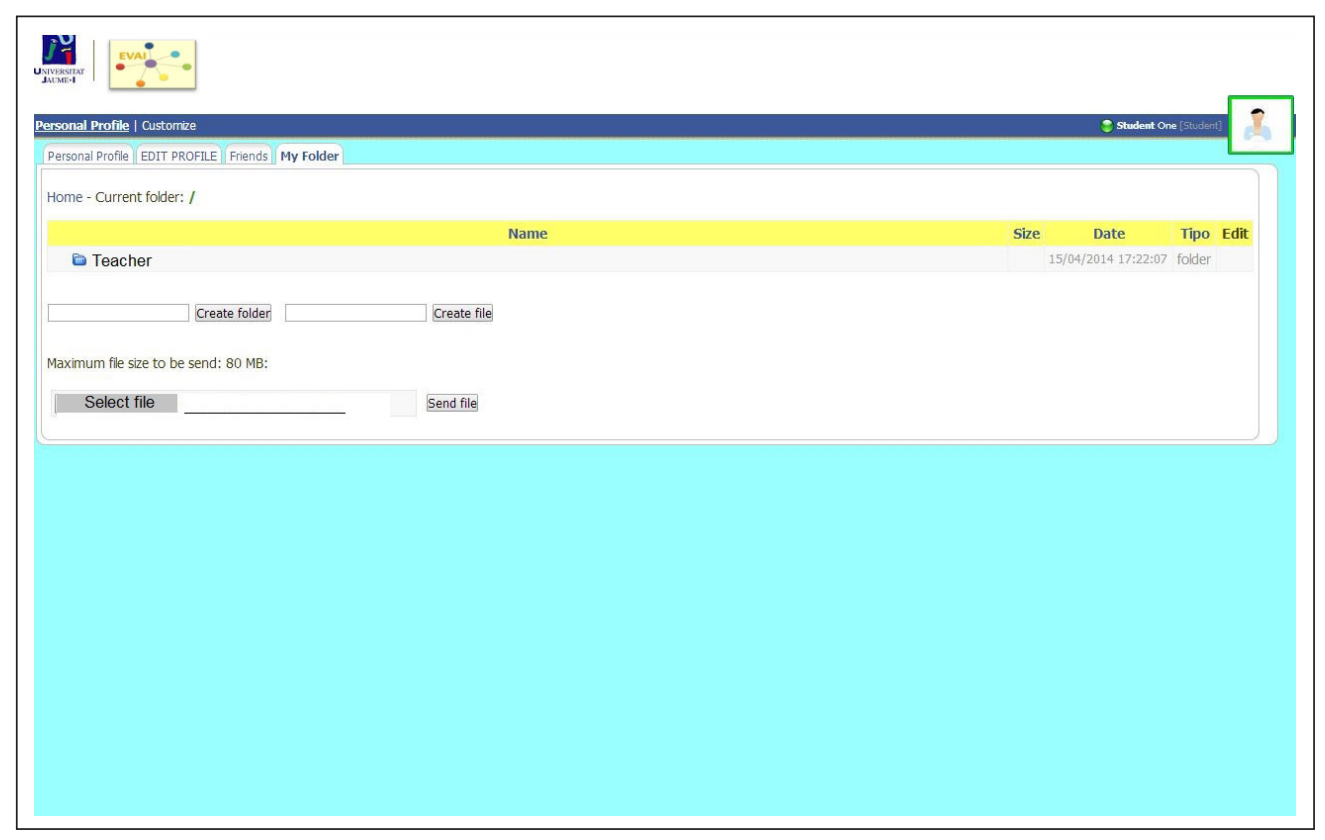

Figure 32. Folder for contents of the students 
by the teacher must be uploaded to the folder for that subject. No new folders must be created and the files have to be uploaded one-by-one, otherwise the teacher will be unable to see them.

\section{CHOOSE SUBJECT}

This subsection shows the list of all the subjects that are active for the user (Figure 33).

Each of them can be accessed by clicking on the name of the subject.

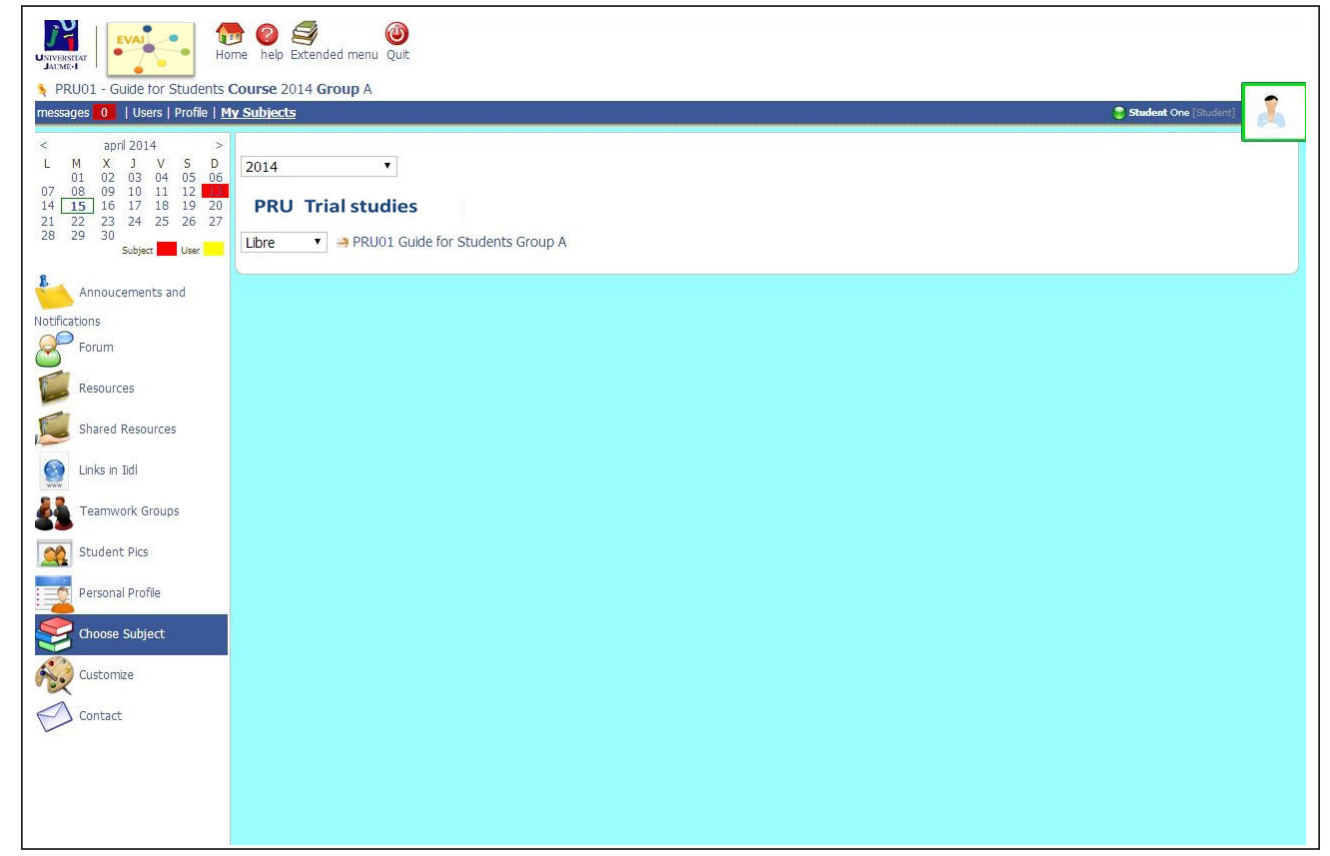

Figure 33. Choose subjet for student

\section{PERSONALISE}

Selecting this subsection will open up a new tab beside the main page that will allow us to personalise the appearance of the environment according to our own preferences (background colour and the icons in the top taskbar). See Figure 34.

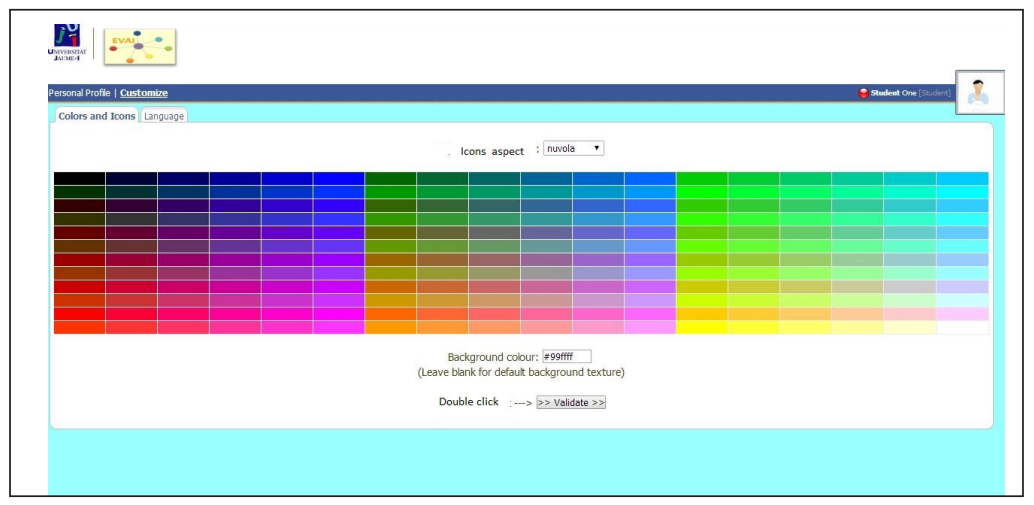

Figure 34. Customizing menu 
Once we have selected the theme for the icons and/or the background colour (by clicking on the desired colour), we should validate the changes, close the tab and refresh the main page.

\section{CONTACT}

This subsection allows us access to the email address of the lecturer responsible for the active subject, as well as that of the administrator (Figure 35).

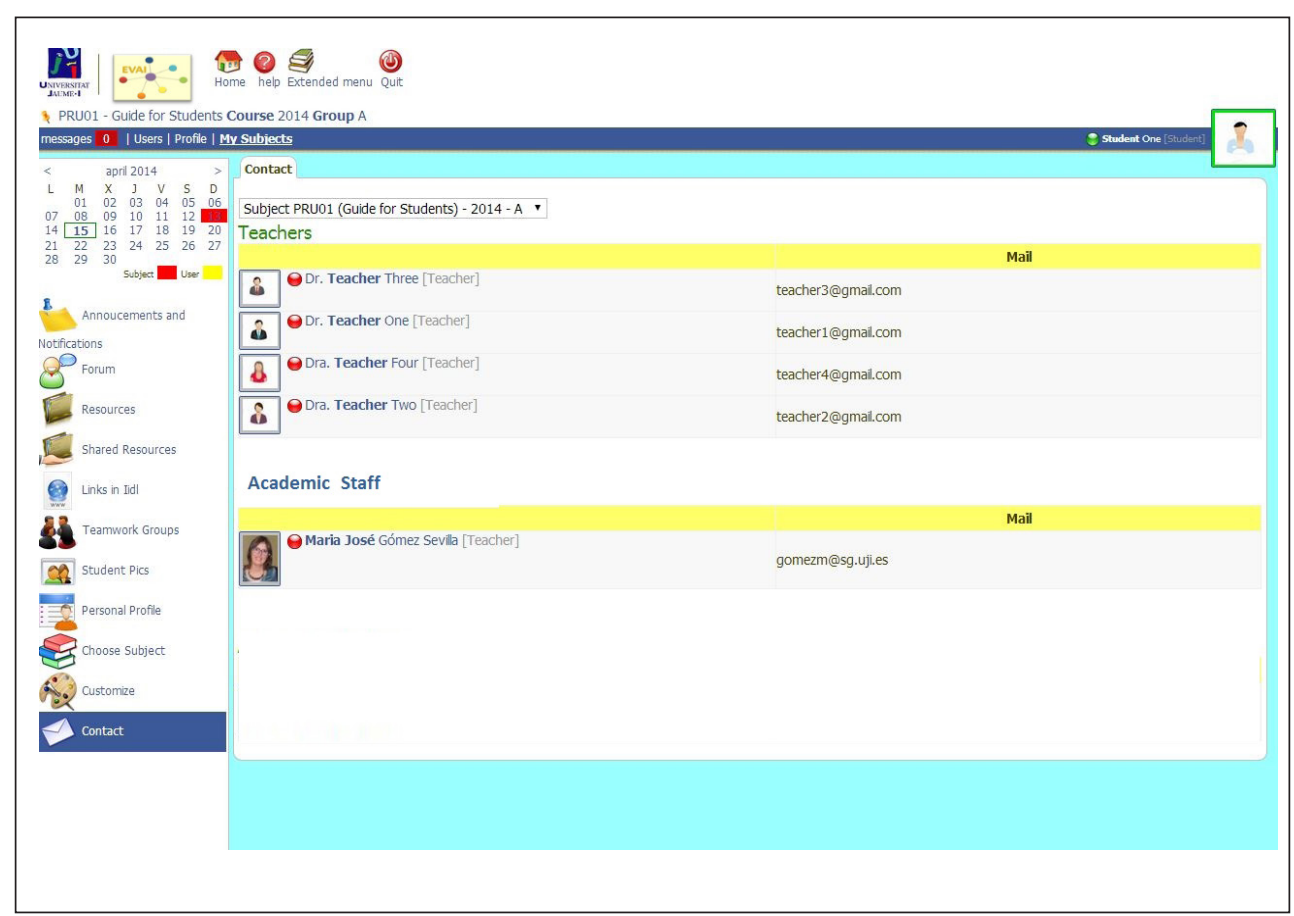

Figure 35. Contact with teachers and academic staff

Choosing the degree on the dropdown menu that appears in the upper part of the screen will grant us access to the contact information of all the members of the teaching staff involved in the course, as well as the administrator.

Clicking on the picture of any of the contacts will afford us direct access to their personal homepage. 


\section{ju \\ UNIVERSITAT JAUME•I}

The EVAI platform is a virtual learning (e-learning) environment based on open-source free software. At the software level, and like other platforms such as Moodle, it uses the Internet infrastructure system known as WAMP (Windows, Apache, MySql/MariaDB and PHP). This means that is an Open Source Project.

But also, the EVAI is an active, dynamic, constantly mutating project whose operative manifestation is the virtual platform we present here as it stands today. The EVAl is not just an online teaching-learning "platform". Rather, it is a teaching and learning philosophy that is shared and experienced in real time and which renews and regenerates itself through the interaction among its users (teaching staff and learners). It is at the same time both pragmatic and abstract because it gradually constructs itself, day by day, as we think, use it and represent it.

Conceived in this way, then, the EVAI is also an open project that attempts to uncover the new realities that emerge with the intensive and innovative use of the ICKTs in Education. This is accomplished by becoming immersed in both the virtual and the real face-to-face world, and by learning to make sense - in real time - of the different patterns that are formed. In sum, the EVAI is part of a dynamic, constantly evolving project. Its development is the result of the research, experimentation and ideas that have arisen from its use by teaching staff and students, since it is the "virtual classroom" in different graduate and postgraduate courses (Official and Universityspecific courses at the Universitat Jaume I). 